\title{
Empirical relations of rock properties of outcrop and core samples from the Northwest German Basin for geothermal drilling
}

\author{
D. Reyer ${ }^{1, *}$ and S. L. Philipp ${ }^{1}$ \\ ${ }^{1}$ Georg August University of Göttingen, Geoscience Centre, Department of Structural Geology and \\ Geodynamics, Germany \\ *now at: State Authority of Mining, Energy and Geology - Zentrum für TiefenGeothermie, Celle, Germany \\ Correspondence to: D. Reyer (dorothea.reyer@geo.uni-goettingen.de)
}

Received: 26 March 2013 - Revised: 12 August 2014 - Accepted: 15 August 2014 - Published: 8 September 2014

\begin{abstract}
Information about geomechanical and physical rock properties, particularly uniaxial compressive strength (UCS), are needed for geomechanical model development and updating with logging-while-drilling methods to minimise costs and risks of the drilling process. The following parameters with importance at different stages of geothermal exploitation and drilling are presented for typical sedimentary and volcanic rocks of the Northwest German Basin (NWGB): physical ( $P$ wave velocities, porosity, and bulk and grain density) and geomechanical parameters (UCS, static Young's modulus, destruction work and indirect tensile strength both perpendicular and parallel to bedding) for 35 rock samples from quarries and 14 core samples of sandstones and carbonate rocks.

With regression analyses (linear- and non-linear) empirical relations are developed to predict UCS values from all other parameters. Analyses focus on sedimentary rocks and were repeated separately for clastic rock samples or carbonate rock samples as well as for outcrop samples or core samples. Empirical relations have high statistical significance for Young's modulus, tensile strength and destruction work; for physical properties, there is a wider scatter of data and prediction of UCS is less precise. For most relations, properties of core samples plot within the scatter of outcrop samples and lie within the $90 \%$ prediction bands of developed regression functions. The results indicate the applicability of empirical relations that are based on outcrop data on questions related to drilling operations when the database contains a sufficient number of samples with varying rock properties. The presented equations may help to predict UCS values for sedimentary rocks at depth, and thus develop suitable geomechanical models for the adaptation of the drilling strategy on rock mechanical conditions in the NWGB.
\end{abstract}

\section{Introduction}

In Germany, the North German Basin (NGB) is one region with considerable geothermal low-enthalpy potential (Paschen et al., 2003). To utilise this potential, deep wellbores have to be drilled to reach prospective geothermal reservoir rocks at depths of 3000-6000 m. Well construction is therefore the main expense factor of geothermal projects in this region. In sedimentary successions such as the NGB, one of the major problems and expenditures may be related to wellbore stability issues (e.g. Dusseault, 2011; Zeynali, 2012). Such wellbore instabilities are recognised as a drilling challenge that may considerably increase drilling costs and safety risks (Proehl, 2002; York et al., 2009; Li et al., 2012). The profit margin of geothermal projects, however, is rather small compared with hydrocarbon projects. Therefore, a substantial reduction of costs for well construction and completion is desirable (cf. www.gebo-nds.de).

Evaluation of in situ rock mechanical behaviour requires different information. Important input data include estimates of mechanical conditions, pore pressures, and stress state. According to Zeynali (2012), two of the most important mechanical factors affecting wellbore stability are the mechanical properties of rock - including anisotropy of strengths and 
elastic moduli (e.g. Heap et al., 2010) - and in situ stresses existing in different layers of rock. Development of a geomechanical model before starting the drilling operation is a powerful tool to prevent wellbore instabilities and minimise drilling costs of geothermal wells (Khaksar et al., 2009). For drilling through a rock mass, such model captures the initial equilibrium state that describes the stresses, pore pressure, and geomechanical properties. With logging-while-drilling data the initially computed geomechanical model can be continuously adapted to the conditions at depth.

For such geomechanical modelling, the uniaxial compressive strength (UCS) is the most important geomechanical input parameter (Chang et al., 2006; Nabaei and Shahbazi, 2012; Vogt et al., 2012). There already exist several software approaches for building and updating geomechanical models (Settari and Walters, 2001; geomechanics software, e.g. GMI - http://www.baker-hughes.com). Generally, such geomechanical modelling software uses empirical relationships that were developed for hydrocarbon reservoirs. To date there do not exist such relationships for geothermal reservoirs of the NGB. Here, the geological setting may be completely different leading to other rock mechanical conditions. Therefore, existing methods for geomechanical modelling have to be reviewed carefully and adapted where needed.

There are several relevant parameters with importance given to different stages of geothermal exploitation and drilling. Physical properties such as density, $\rho$, and $P$ and $S$ wave velocities, $v_{\mathrm{p}}$ and $v_{\mathrm{s}}$ (compressional and shear wave velocities), are parameters that can be measured directly in wellbores; the porosity, $\Phi$, is derivable from such well logs (Edlmann et al., 1998). The dynamic Young modulus is derived from velocity and density logs (Fricke and Schön, 1999; Zoback, 2007; Rider and Kennedy, 2011). Geomechanical parameters are important for reservoir exploitation and drilling operations. The static Young modulus, $E_{\mathrm{s}}$, is interesting in terms of predictions of fracture propagation (Jaeger et al., 2007; Gudmundsson, 2011). The indirect tensile strength, $T_{0}$, gives information about the rock's resistance to tensile fractures. These parameters are of interest in terms of dimensioning of hydraulic fracturing operations, wellbore stability and drilling mud selection (e.g. Zoback, 2007). The destruction work, $W$, is one parameter providing information on the amount of energy needed to destroy the rock while drilling. It is known to correlate with the drilling efficiency which is a term used to describe the effects of a number of geological and machine parameters on the drilling velocity (Thuro, 1997). Therefore, it is desirable to make reasonable assumptions about these parameters for drilling through the rock units. To do so, we need empirical relations between UCS and parameters which are either knowable before drilling or determinable with loggingwhile-drilling tools. With well logs from existing adjacent boreholes, a geomechanical model can be built using empirical relations between rock-strength values and physical parameters. Empirical relations can then be used for validation of the geomechanical model while- and after-drilling by updating the model continuously with logging data.

Determining geomechanical and physical parameters directly from core material, however, is expensive and timeconsuming because a large number of core samples are needed, and core material is rare (e.g. Khaksar et al., 2009). Therefore, in this study we aim to improve predictions of mechanical properties for rocks at depth. First, we present data on geomechanical and physical properties of representative rock types of the NGB. We sampled 35 mainly sedimentary rocks of the western sub-basin of the NGB, the Northwest German Basin (NWGB), from Lower Permian to Upper Cretaceous, exposed in outcrop analogues, i.e. quarries. In addition to these outcrop samples, we analysed 14 core samples from two wellbores with the same stratigraphic units, comparable lithologies and facies as equivalent samples to analyse mechanical property changes due to uplift and alteration. Secondly, we used the data of sedimentary rocks to perform regression analyses, together with calculation of coefficients of determination $\left(R^{2}\right)$, between UCS and the described parameters, separately for outcrop samples only and including core samples. To analyse the statistical significance of the developed regression functions, $90 \%$ confidence and prediction bands are added. The rock properties of core samples are compared with the results of outcrop samples from the developed equations of outcrop samples to examine the relevance of outcrop samples for predicting rock properties at depths. The regression functions may help predict UCS values for sedimentary rocks at depth, and thus develop a suitable geomechanical model for the adaptation of the drilling strategy on rock mechanical conditions.

\section{Geologic setting and sample locations}

The study area is part of the NWGB, the western part of the NGB, located in northwestern Germany (Walter, 2007). The NGB initiated in the Late Carboniferous-Permian due to rifting processes subsequent to the Variscan orogenesis (Betz et al., 1987; Ziegler, 1990). From marine to continental conditions, the sedimentary succession is characterised by changing sedimentation environments. Therefore, the NWGB is comprised of mainly carbonate and clastic rocks with some intercalated evaporates leading to very heterogeneous rock mechanical conditions.

The study area is located at the southern and western margins of the western region of the North German Basin (Fig. 1; cf. Reyer et al., 2012). Sedimentary rocks that occur at geothermally relevant depths in the centre and north of the NWGB crop out at the basin margins and can be sampled in quarries. In such outcrop analogues, listed in Table 1, we took samples of two main rock types: carbonate rocks (Triassic, Jurassic, and Cretaceous age) and sandstones (Permian, Triassic, Jurassic, and Cretaceous age; Table 1). Three Rotliegend volcanic rock (Permian) samples are included to 


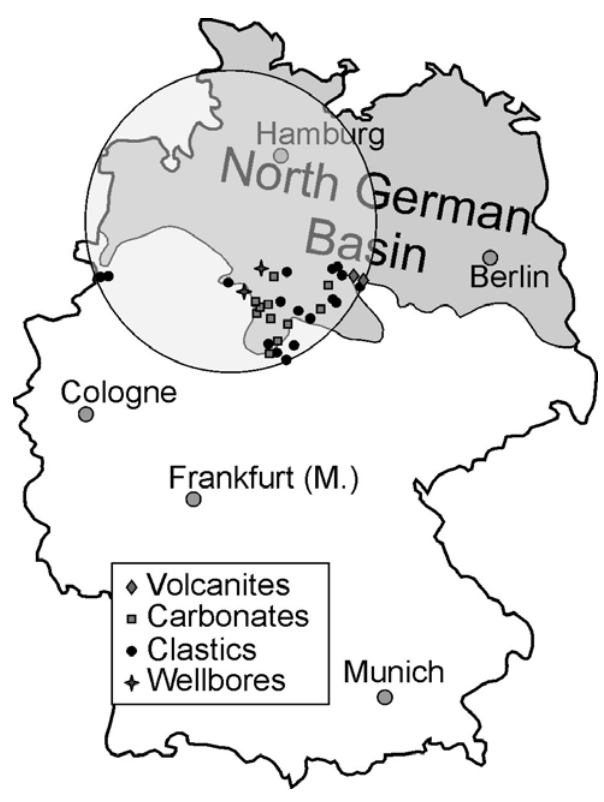

Figure 1. North German Basin (modified after http://www.geotis. de) with the locations of sampled wellbores and quarries and the exposed rock types (see key) in the NWGB (rough location marked).

obtain rock property data over a wide range of lithologies present in the NWGB (Fig. 1). For four carbonate rock units and three sandstone units, the equivalent core samples were identified and sampled from two wellbores: Groß Buchholz (Gt1) and Eulenflucht 1 (EF1; Table 1).

\section{Methods}

\subsection{Density and porosity}

The bulk density, $\rho_{\mathrm{d}}\left[\mathrm{g} \mathrm{cm}^{-3}\right]$, was determined from dry cylindrical specimens with a GeoPyc 1360 (Micromeritics), setting measured volume and mass in relation. For the same specimens, we measured the grain density, $\rho_{0}\left[\mathrm{~g} \mathrm{~cm}^{-3}\right]$, with an Ultrapycnometer 1000 (Quantachrome) at room temperature using $99.9 \%$ helium, previously measured $\rho_{\mathrm{d}}$ and specimen's mass.

The total porosity, $\Phi$, given in [\%], was calculated from $\rho_{0}$ and $\rho_{\mathrm{d}}$. Samples are separated in low- $(0-10 \%)$, medium$(10-20 \%)$, and high-porosity (> 20\%) rocks for further interpretation of rock properties.

\subsection{Rock testing}

Uniaxial compression tests were performed stress-controlled at a constant rate of $0.5 \mathrm{MPa} \mathrm{s}^{-1}$ on specimens with lengthdiameter ratios of 2-2.5 to determine UCS and $E_{\mathrm{S}}$ (ISRM, 2007). For each outcrop sample, six specimens with diameters of $40 \mathrm{~mm}$ were measured, both parallel and perpendicular to sedimentary bedding or, for volcanic rocks, with respect to surface orientation. Core samples were tested only perpendicular to bedding due to limited core material. $v_{\mathrm{p}}$ is measured (Tektronix TDS 5034B; $1 \mathrm{MHz}$ rectangular pulse) to eliminate defective specimens. $E_{\mathrm{S}}$ is determined at the linear-elastic deformation path of the stress-strain curve. For rock samples showing brittle failure, we calculated $W$ (Thuro, 1997) as the area below the stress-strain curve given in kilojoules per cubic metre.

$T_{0}$ is measured both parallel and perpendicular to sedimentary bedding on specimens with diameters of $40 \mathrm{~mm}$ and lengths of $15-20 \mathrm{~mm}$ with Brazilian tests (ISRM, 2007). Both parallel and perpendicular to bedding, a minimum of nine (outcrop samples) and four specimens (core samples), respectively, were tested.

\subsection{Statistical analyses}

For each sample, both parallel and perpendicular to bedding, mean values and standard deviations of the tested specimens were calculated for geomechanical parameters and $v_{\mathrm{p}}$. We performed regression analyses (linear and non-linear) of mean values for UCS with $\Phi, \rho_{\mathrm{d}}, v_{\mathrm{p}}$, and $E_{\mathrm{S}}$ and for $W$ and $T_{0}$ with UCS, respectively. Different regression analyses were made for each pair of parameters: (1) all samples to obtain a good overview, (2) sandstone samples only, and (3) carbonate samples only. In each case, regressions were made both for outcrop samples only and for all samples including core samples. For outcrop sample equations, $90 \%$ confidence and prediction bands are included. Confidence bands represent the $90 \%$ certainty of regression curve estimation based on limited sample data (Wooldridge, 2009; Brink, 2010). Prediction bands cover the range in which the values of future measurements of associated samples lie with a probability of $90 \%$. Based on these bands core sample results are compared with outcrop results.

\section{Experimental results}

\subsection{Physical properties}

In Tables 2 and 3, mean values of dry bulk density, grain density, calculated porosities, and $P$ wave velocities of all rock samples are listed. The approximate lithology is given to better appraise the following data analyses.

For sandstones and carbonates, we have sample data over a wide range of porosities; the lowest porosities occur in core samples. Accordingly, the dry bulk density values show a wide range. Grain densities of carbonates are highest due to a higher mineral density of the carbonates' main component calcite as compared with quartz. The grain densities strongly depend on the amount of heavy minerals: (1) hematite-rich Triassic sandstones have high $\rho_{0}$ values $\left(>2.7 \mathrm{~g} \mathrm{~cm}^{-3}\right)$; (2) carbonate samples with increased grain densities contain large amounts of ferrous carbonates.

$v_{\mathrm{p}}$ values clearly depend on lithology. Carbonate samples show mean values of $v_{\mathrm{p}}$ from $3277 \mathrm{~m} \mathrm{~s}^{-1}$ (porous chalk marl: 
Table 1. All samples from outcrops and wellbores with sample ID, local name, lithology, stratigraphical units, and total vertical depths of core samples.

\begin{tabular}{|c|c|c|c|c|}
\hline Sample ID & Lithology & System & Local name & \\
\hline $\mathrm{KrCa}$ & Chalk marl & \multirow{8}{*}{ Cretaceous } & \multicolumn{2}{|l|}{ Kreidemergel } \\
\hline GoSa & Sandstone & & \multicolumn{2}{|l|}{ Sudmerberg F. } \\
\hline HoT & Marl & & \multicolumn{2}{|l|}{ Rotpläner } \\
\hline $\mathrm{BrCe}$ & Limestone & & \multicolumn{2}{|l|}{ Cenoman-Kalk } \\
\hline OLH & Sandstone & & \multicolumn{2}{|l|}{ Hils Sst. } \\
\hline GiUK & Sandstone & & \multicolumn{2}{|l|}{ Gildehaus Sst. } \\
\hline FrUK & Sandstone & & \multicolumn{2}{|l|}{ Bentheimer Sst. } \\
\hline $\mathrm{OK}$ & Sandstone & & \multicolumn{2}{|l|}{ Wealden Sst. } \\
\hline ThüJ & Limestone & \multirow{6}{*}{ Jurassic } & \multicolumn{2}{|l|}{ Serpulit } \\
\hline GVa & Limestone & & \multicolumn{2}{|l|}{ Gigas Schichten } \\
\hline OKDa & Limestone & & \multicolumn{2}{|l|}{ Oberer Kimmeridge } \\
\hline ShJk & Limestone & & \multicolumn{2}{|l|}{ Korallenoolith } \\
\hline HSDi, HSDi2 & Limestones & & \multicolumn{2}{|l|}{ Heersumer Schichten } \\
\hline AlWo & Sandstone & & \multicolumn{2}{|l|}{ Aalen Sst. } \\
\hline koQ & Sandstone & \multirow{12}{*}{ Triassic } & \multicolumn{2}{|l|}{ Rhät Sst. } \\
\hline koVe & Sandstone & & \multicolumn{2}{|l|}{ Rhät Sst. } \\
\hline kuWe & Siltstone & & \multicolumn{2}{|l|}{ Lettenkohlen Sst. } \\
\hline EM & Limestone & & \multicolumn{2}{|l|}{ Trochitenkalk } \\
\hline $\mathrm{H}$ & Limestone & & \multicolumn{2}{|l|}{ Schaumkalk } \\
\hline EL1, EL2, EL3 & Limestones & & \multicolumn{2}{|l|}{ Wellenkalk } \\
\hline soWa & Shale-Gypsum & & \multicolumn{2}{|l|}{ Röt 1} \\
\hline smHN & Sandstone & & Hardegsen-Folge & \\
\hline $\mathrm{smD}$ & Sandstone & & Detfurth-Folge & \\
\hline smVG, smVG2 & Sandstones & & Volpriehausen-Folge & \\
\hline suHe & Limestone & & Rogenstein & \\
\hline $\mathrm{BiSu}$ & Sandstone & & Bernburg-Folge & \\
\hline BeRo, BeRoK & Sandstones & & Rotliegend Sst. & \\
\hline DöRo & Andesite & Permian & Rotliegend-Vulkanit & \\
\hline FL2, FL6 & Rhyolites & & Rotliegend-Vulkanit & \\
\hline & Wellbore 1: Eul & nflucht 1 (EF1) & & \\
\hline & Wellbore 2: Gro & Buchholz (Gt1) & & $\operatorname{TVD}[\mathrm{m}]$ \\
\hline Gt1WS1 & Sandstone & & Wealden Sst. & 1.221 \\
\hline Gt1WS2 & Sandstone & Cretaceous & Wealden Sst. & 1.211 \\
\hline EF1WS & Sandstone & & Wealden Sst. & 135 \\
\hline EF1GS & Limestone & & Gigas Schichten & 210 \\
\hline EF1OK & Limestone & & Oberer Kimmeridge & 243 \\
\hline EF1UKK & Limestone & Jurassic & Korallenoolith & 282 \\
\hline EF1KO & Limestone & & Korallenoolith & 286 \\
\hline EF1HS & Limestone & & Heersumer Schichten & 325 \\
\hline Gt1DU1 & Sandstone & & Detfurth-Folge & $\sim 3535.8$ \\
\hline Gt1DU2 & Sandstone & & Detfurth-Folge & $\sim 3534.3$ \\
\hline Gt1DU3 & Sandstone & Triassic & Detfurth-Folge & $\sim 3534.7$ \\
\hline Gt1DW & Siltstone & & Detfurth-Folge & $\sim 3537.2$ \\
\hline Gt1VS1 & Sandstone & & Volpriehausen-Folge & $\sim 3655.6$ \\
\hline Gt1VS2 & Sandstone & & Volpriehausen-Folge & $\sim 3657.8$ \\
\hline
\end{tabular}

Sst.: sandstone, F.: formation; TVD: total vertical depth 
Table 2. Lithology, dry bulk density, grain density, porosity and $P$ wave velocity for outcrop samples.

\begin{tabular}{|c|c|c|c|c|c|}
\hline Sample ID & Specified lithology & $\rho_{\mathrm{d}}\left[\mathrm{g} \mathrm{cm}^{-3}\right]$ & $\rho_{0}\left[\mathrm{~g} \mathrm{~cm}^{-3}\right]$ & $\Phi[\%]$ & $v_{\mathrm{p}}\left[\mathrm{ms}^{-1}\right]+\mathrm{SD}$ \\
\hline $\mathrm{KrCa}$ & Porous chalk marl & 2.18 & 2.86 & 23.9 & $3277 \pm 84$ \\
\hline $\mathrm{GoSa}$ & Medium-grained sandstone & 2.53 & 2.69 & 6 & $3772 \pm 70$ \\
\hline HoT & Marl & 2.59 & 2.73 & 5.2 & $5116 \pm 199$ \\
\hline $\mathrm{BrCe}$ & Bioclast-bearing matrix LS & 2.66 & 2.77 & 3.8 & $4674 \pm 258$ \\
\hline $\mathrm{OLH}$ & Medium-grained sandstone & 2.09 & 2.77 & 24.6 & $2291 \pm 63$ \\
\hline GiUK & Medium-grained sandstone & 2.11 & 2.68 & 21.6 & $2576 \pm 130$ \\
\hline FrUK & Fine-grained sandstone & 2.36 & 2.68 & 12.1 & $2172 \pm 87$ \\
\hline $\mathrm{OK}$ & Medium-grained sandstone & 2.29 & 2.80 & 18.3 & $2942 \pm 120$ \\
\hline ThüJ & Bioclast-rich matrix LS & 2.07 & 2.83 & 26.7 & $4262 \pm 215$ \\
\hline GVa & Porous sparry LS & 2.29 & 2.96 & 22.8 & $3967 \pm 106$ \\
\hline OKDa & Bioclast-rich matrix LS & 2.63 & 2.83 & 7.2 & $5134 \pm 100$ \\
\hline ShJk & Bioclast-bearing oolite & 2.61 & 2.74 & 4.6 & $5171 \pm 154$ \\
\hline HSDi & Micro-sparry LS & 2.53 & 2.78 & 9.1 & $5084 \pm 350$ \\
\hline HSDi2 & Bioclast-rich sparry LS & 2.40 & 2.78 & 13.7 & $4787 \pm 236$ \\
\hline AlWo & Medium-grained sandstone & 2.09 & 2.69 & 22.5 & $3000 \pm 184$ \\
\hline koQ & Medium-grained sandstone & 2.27 & 2.84 & 20.1 & $3222 \pm 36$ \\
\hline koVe & Fine-grained sandstone & 2.34 & 2.77 & 15.6 & $2980 \pm 38$ \\
\hline kuWe & Siltstone & 2.59 & 2.68 & 3.4 & $3951 \pm 126$ \\
\hline EM & Bioclast-rich sparry LS & 2.71 & 2.79 & 2.9 & $5607 \pm 164$ \\
\hline $\mathrm{H}$ & Porous sparry LS & 2.40 & 2.77 & 13.2 & $4888 \pm 73$ \\
\hline EL1 & Dolomitic LS & 2.53 & 2.98 & 15.1 & $4683 \pm 133$ \\
\hline EL2 & Massy matrix LS & 2.74 & 2.75 & 0.3 & $6158 \pm 8$ \\
\hline EL3 & Dolomitic LS & 2.66 & 2.94 & 9.4 & $4526 \pm 23$ \\
\hline soWa & Shale-gypsum alternation & 2.33 & 2.39 & 2.5 & $3690 \pm 120$ \\
\hline $\operatorname{smHN}$ & Medium-grained sandstone & 2.26 & 2.71 & 16.6 & $2574 \pm 64$ \\
\hline $\operatorname{smD}$ & Medium-grained sandstone & 2.38 & 2.76 & 13.7 & $2986 \pm 22$ \\
\hline $\operatorname{smVG}$ & Medium-grained sandstone & 2.32 & 2.72 & 14.4 & $2948 \pm 78$ \\
\hline smVG2 & Medium-grained sandstone & 2.17 & 2.74 & 20.6 & $2074 \pm 89$ \\
\hline $\mathrm{suHe}$ & Sparry oolite & 2.71 & 2.75 & 1.5 & $5368 \pm 136$ \\
\hline $\mathrm{BiSu}$ & Medium-grained sandstone & 2.15 & 2.79 & 22.9 & $2110 \pm 6$ \\
\hline BeRoK & Conglomeratic sandstone & 2.58 & 2.67 & 3.2 & $3564 \pm 78$ \\
\hline BeRo & Medium-grained sandstone & 2.52 & 2.69 & 6.6 & $3426 \pm 29$ \\
\hline DöRo & Andesite & 2.72 & 2.72 & 0.1 & $5449 \pm 23$ \\
\hline FL2 & Rhyolite & 2.63 & 2.64 & 0.1 & $5260 \pm 44$ \\
\hline FL6 & Rhyolite & 2.69 & 2.69 & 0.1 & $5342 \pm 64$ \\
\hline
\end{tabular}

LS, limestone; $\rho_{\mathrm{d}}$, dry bulk density; $\rho_{0}$, grain density; $\Phi$, porosity; $v_{\mathrm{p}}, P$ wave velocity; SD, standard deviation

$\mathrm{KrCa}$ ) to $6158 \mathrm{~m} \mathrm{~s}^{-1}$ (massy matrix limestone: EL2). Mostly, the standard deviations of carbonate samples are high. This is pronounced in carbonates with either a high presence of lithoclasts or due to rock heterogeneities. $v_{\mathrm{p}}$ in sandstones are considerably slower than in carbonate rocks. The lowest values relate to high porosities. In volcanic rock samples, $v_{\mathrm{p}}$ is rather high (about $5300 \mathrm{~m} \mathrm{~s}^{-1}$ ) with small variation and standard deviations.

\subsection{Rock mechanical properties}

In Table 4, mean values of the geomechanical parameters of all samples are listed. The standard deviations of all measurements for every sample are given. Measured parameter values of the eight clastic core samples are higher than those of the 14 outcrop samples. The differences between outcrop and core samples of carbonate rocks are, in contrast, rather small. Parameter values of the three volcanic rock samples are considerably higher than of sedimentary outcrop samples.

\section{Empirical relations of rock properties with UCS}

The rock property data, presented in Tables 2,3 , and 4, may be used directly to calibrate an existing geomechanical model by attaching UCS values to log profiles and deducing equivalent values of tensile strength and destruction work using empirical relations. In situ rocks and core samples, however, may have completely different rock properties. Thus, we compare properties of core samples and outcrop samples to analyse if properties of in situ rocks can be predicted based on data from outcrop samples from the same geologic setting. 
Table 3. Lithology, dry bulk density, grain density, porosity and $P$ wave velocity for core samples.

\begin{tabular}{|c|c|c|c|c|c|}
\hline \multicolumn{6}{|c|}{ Core samples: } \\
\hline Sample ID & Specified lithology & $\rho_{\mathrm{d}}\left[\mathrm{g} \mathrm{cm}^{-3}\right]$ & $\rho_{0}\left[\mathrm{~g} \mathrm{~cm}^{-3}\right]$ & $\Phi[\%]$ & $v_{\mathrm{p}}\left[\mathrm{ms}^{-1}\right]+\mathrm{SD}$ \\
\hline Gt1WS1 & Coarse-grained sandstone & 2.40 & 2.84 & 15.5 & $4854 \pm 38$ \\
\hline Gt1WS2 & Medium-grained sandstone & 2.58 & 2.79 & 7.6 & $2950 \pm 267$ \\
\hline EF1WS & Medium-grained sandstone & 2.25 & 2.79 & 19.4 & $2638 \pm 28$ \\
\hline EF1MM & Shale gypsum & 2.88 & 2.95 & 2.4 & $5808 \pm 110$ \\
\hline EF1GS & Sparry LS & 2.48 & 2.78 & 10.8 & $5832 \pm 65$ \\
\hline EF1OK & Bioclast-rich matrix LS & 2.72 & 2.78 & 2.1 & $5732 \pm 50$ \\
\hline EF1UKK & Bioclast-rich sparry LS & 2.76 & 2.77 & 0.2 & $5412 \pm 53$ \\
\hline EF1KO & Sparry oolite & 2.72 & 2.79 & 2.6 & $6053 \pm 59$ \\
\hline EF1HS & Bioclast-rich sparry LS & 2.18 & 2.82 & 22.8 & $3831 \pm 87$ \\
\hline Gt1DU1 & Medium-grained sandstone & 2.69 & 2.70 & 0.4 & $4981 \pm 33$ \\
\hline Gt1DU2 & Coarse-grained sandstone & 2.73 & 2.75 & 1.0 & $3410 \pm 78$ \\
\hline Gt1DU3 & Medium-grained sandstone & 2.67 & 2.77 & 3.6 & $4906 \pm 96$ \\
\hline Gt1DW & Siltstone & 2.83 & 2.87 & 1.1 & $5166 \pm 123$ \\
\hline Gt1VS1 & Medium-grained sandstone & 2.71 & 2.72 & 0.1 & $4745 \pm 62$ \\
\hline Gt1VS2 & Coarse-grained sandstone & 2.69 & 2.77 & 2.8 & $4539 \pm 54$ \\
\hline
\end{tabular}

LS, limestone; $\rho_{\mathrm{d}}$, dry bulk density; $\rho_{0}$, grain density; $\Phi$, porosity; $v_{\mathrm{p}}, P$ wave velocity; SD, standard deviation
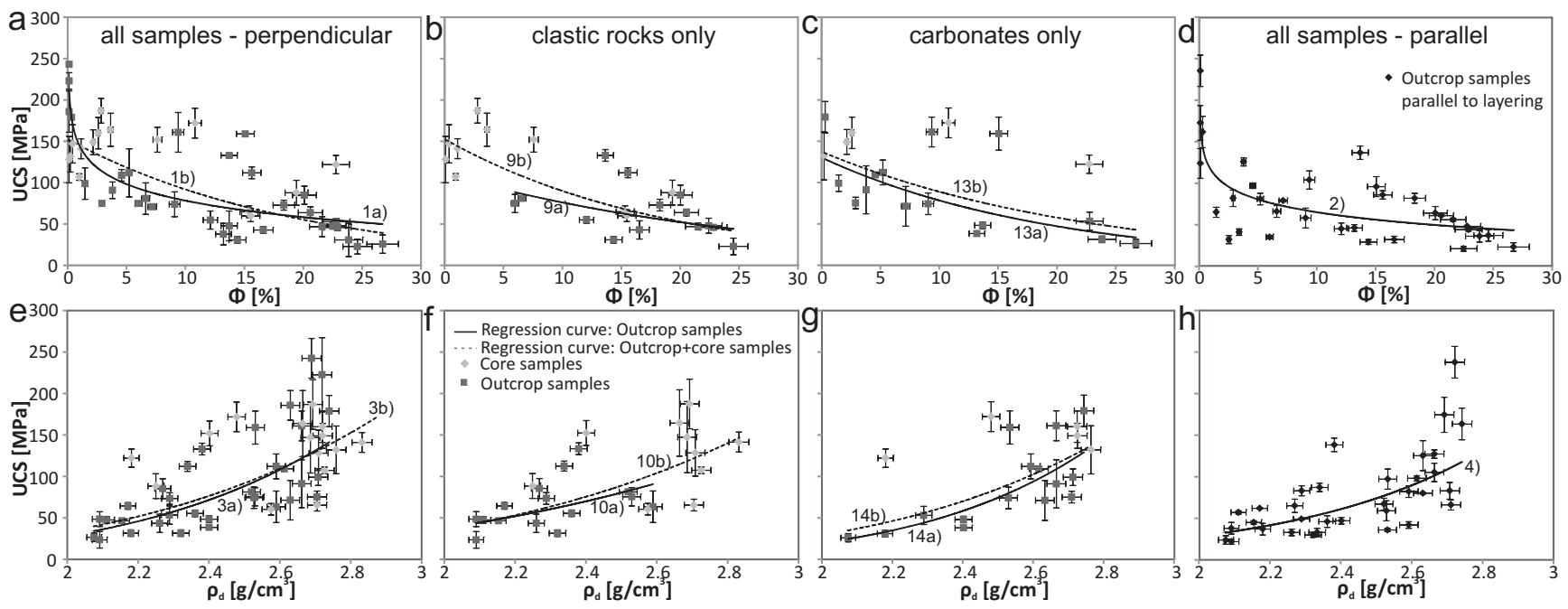

Figure 2. UCS measured perpendicular to bedding vs. (a-c) $\Phi$ and (e-g) $\rho_{\mathrm{d}}$, respectively, separately for all samples $(\mathbf{a}, \mathbf{e} ; n=49)$, only clastic rock samples $(\mathbf{b}, \mathbf{f} ; n=24)$ and only carbonate samples $(\mathbf{c}, \mathbf{g} ; n=20)$ for outcrop and core samples; regression curves shown for both outcrop and core samples and outcrop samples only. UCS measured parallel to bedding vs. (d) $\Phi$ and (h) $\rho_{\mathrm{d}}(n=33)$; for regression equations see Table 5. For UCS, error bars stand for standard deviations of all measurements of every sample (Table 4). For density and porosity, error bars represent measuring accurancies of $1 \%$ and $5 \%$, respectively.

In Table 5, the results of regression analyses for the different parameters, presented in following sections, are summarised.

\subsection{Empirical relations for UCS prediction}

\subsubsection{Density and porosity}

Porosity and bulk density are two parameters that can be determined with geophysical logs. Many previous studies showed that there are strong correlations between UCS and both parameters (e.g. Lama and Vutukuri, 1978; Jizba, 1991; Wong et al., 1997; Palchik, 1999).

In Fig. 2, both porosity and bulk density are plotted against UCS measured perpendicular and parallel to bedding. It is obvious that there is a wide scatter of data resulting in rather poor statistical significance of the empirical relations (Table 5). However, the prediction of in situ properties based on outcrop sample results is one of the main questions of this study. It is conspicuous that in all cases, and especially for carbonates, outcrop and core samples show a similar range 
Table 4. Mean values of the geomechanical parameters UCS, Young's modulus, destruction work, and indirect tensile strength, measured perpendicular and parallel to bedding, for all samples including standard deviations.

\begin{tabular}{|c|c|c|c|c|c|c|c|c|}
\hline \multirow{2}{*}{$\begin{array}{l}\text { Sample } \\
\text { ID }\end{array}$} & \multicolumn{2}{|c|}{$\mathrm{UCS} \pm \mathrm{SD}[\mathrm{MPa}]$} & \multicolumn{2}{|c|}{$E_{\mathrm{s}} \pm \mathrm{SD}[\mathrm{GPa}]$} & \multicolumn{2}{|c|}{$W \pm \mathrm{SD}\left[\mathrm{kJ} \mathrm{m}^{-3}\right]$} & \multicolumn{2}{|c|}{$T_{0} \pm \mathrm{SD}[\mathrm{MPa}]$} \\
\hline & par. & perp. & par. & perp. & par. & perp. & par. & perp. \\
\hline $\mathrm{KrCa}$ & $36 \pm 7$ & $31 \pm 4$ & $12.7 \pm 1.2$ & $13.5 \pm 1.1$ & $106 \pm 20$ & $133 \pm 30$ & $2.0 \pm 0.6$ & $2.7 \pm 0.8$ \\
\hline GoSa & $35 \pm 2$ & $75 \pm 11$ & $7.9 \pm 0.5$ & $30.3 \pm 11.1$ & $215 \pm 26$ & $213 \pm 41$ & $2.6 \pm 0.4$ & $5.9 \pm 0.3$ \\
\hline HoT & $81 \pm 7$ & $112 \pm 15$ & $40.6 \pm 4.2$ & $34.1 \pm 6.8$ & $263 \pm 60$ & $332 \pm 67$ & $5.2 \pm 1.0$ & $8.0 \pm 1.7$ \\
\hline $\mathrm{BrCe}$ & $126 \pm 5$ & $91 \pm 29$ & $44.1 \pm 4.0$ & $26.8 \pm 6.1$ & $282 \pm 17$ & $301 \pm 15$ & $6.7 \pm 0.9$ & $7.6 \pm 0.6$ \\
\hline OLH & $37 \pm 7$ & $23 \pm 10$ & $15.1 \pm 5.5$ & $10.9 \pm 6.5$ & $118 \pm 19$ & $50 \pm 6$ & $3.1 \pm 0.3$ & $3.1 \pm 0.3$ \\
\hline GiUK & $56 \pm 2$ & $47 \pm 4$ & $19.7 \pm 4.6$ & $15.7 \pm 2.1$ & $175 \pm 25$ & $198 \pm 41$ & $4.1 \pm 0.4$ & $3.1 \pm 0.2$ \\
\hline FrUK & $45 \pm 7$ & $55 \pm 4$ & $12.0 \pm 3.5$ & $13.7 \pm 4.5$ & $245 \pm 21$ & $248 \pm 38$ & $2.4 \pm 0.3$ & $2.8 \pm 0.4$ \\
\hline $\mathrm{OK}$ & $82 \pm 6$ & $73 \pm 7$ & $19.3 \pm 1.5$ & $18.0 \pm 2.6$ & $394 \pm 34$ & $404 \pm 17$ & $3.8 \pm 0.9$ & $4.2 \pm 0.8$ \\
\hline ThüJ & $23 \pm 5$ & $26 \pm 5$ & $14.7 \pm 1.3$ & $13.3 \pm 3.9$ & $69 \pm 10$ & $77 \pm 9$ & $2.3 \pm 0.4$ & $2.7 \pm 0.4$ \\
\hline GVa & $48 \pm 1$ & $53 \pm 11$ & $14.5 \pm 2.4$ & $14.9 \pm 4.7$ & $151 \pm 13$ & $174 \pm 36$ & $3.5 \pm 0.6$ & $4.8 \pm 0.4$ \\
\hline OKDa & $79 \pm 1$ & $71 \pm 24$ & $35.6 \pm 6.8$ & $30.2 \pm 1.8$ & $207 \pm 24$ & $137 \pm 20$ & $6.3 \pm 0.6$ & $4.5 \pm 0.6$ \\
\hline ShJk & $97 \pm 3$ & $109 \pm 3$ & $46.4 \pm 3.3$ & $43.4 \pm 8.0$ & $499 \pm 67$ & $558 \pm 91$ & $5.2 \pm 1.1$ & $6.5 \pm 1.0$ \\
\hline HSDi & $58 \pm 12$ & $74 \pm 13$ & $37.3 \pm 6.6$ & $27.7 \pm 0.9$ & $203 \pm 31$ & $317 \pm 21$ & $5.5 \pm 1.5$ & $6.9 \pm 0.7$ \\
\hline HSDi2 & - & $48 \pm 4$ & - & $36.5 \pm 3.8$ & - & $215 \pm 78$ & $4.3 \pm 1.7$ & $6.6 \pm 1.0$ \\
\hline AlWo & $21 \pm 3$ & $48 \pm 9$ & $6.1 \pm 0.9$ & $15.8 \pm 2.5$ & $90 \pm 11$ & $154 \pm 17$ & $1.3 \pm 0.2$ & $4.1 \pm 0.6$ \\
\hline koQ & $64 \pm 8$ & $85 \pm 12$ & $16.1 \pm 1.5$ & $20.1 \pm 1.2$ & $395 \pm 36$ & $378 \pm 60$ & $2.9 \pm 0.5$ & $3.6 \pm 0.7$ \\
\hline koVe & $86 \pm 5$ & $112 \pm 6$ & $20.6 \pm 2.4$ & $24.1 \pm 2.3$ & $638 \pm 53$ & $699 \pm 91$ & $4.4 \pm 0.7$ & $4.9 \pm 1.0$ \\
\hline kuWe & $41 \pm 4$ & $63 \pm 19$ & $17.3 \pm 1.7$ & $20.7 \pm 2.0$ & $202 \pm 5$ & $142 \pm 13$ & $5.9 \pm 1.0$ & $6.0 \pm 0.7$ \\
\hline EM & $82 \pm 10$ & $75 \pm 7$ & $47.0 \pm 4.2$ & $36.9 \pm 4.1$ & $299 \pm 64$ & $339 \pm 54$ & $7.0 \pm 1.8$ & $6.1 \pm 1.2$ \\
\hline $\mathrm{H}$ & $46 \pm 4$ & $38 \pm 1$ & $16.5 \pm 2.6$ & $24.5 \pm 6.5$ & $154 \pm 43$ & $89 \pm 18$ & $4.2 \pm 0.8$ & $4.0 \pm 1.1$ \\
\hline EL1 & $96 \pm 12$ & $159 \pm 20$ & $30.8 \pm 2.5$ & $31.3 \pm 1.2$ & $410 \pm 68$ & $542 \pm 76$ & $5.5 \pm 1.2$ & $10.2 \pm 2.6$ \\
\hline EL2 & $162 \pm 19$ & $179 \pm 19$ & $81.6 \pm 6.5$ & $49.2 \pm 1.4$ & $546 \pm 43$ & $479 \pm 37$ & $7.5 \pm 1.3$ & $9.0 \pm 2.2$ \\
\hline EL3 & - & $104 \pm 11$ & - & $28.6 \pm 2.3$ & - & $424 \pm 53$ & $6.2 \pm 1.5$ & $10.3 \pm 1.9$ \\
\hline soWa & $32 \pm 5$ & - & $20.6 \pm 5.6$ & - & $66 \pm 10$ & - & $2.2 \pm 0.4$ & $4.2 \pm 1.1$ \\
\hline smHN & $32 \pm 4$ & $43 \pm 11$ & $13.4 \pm 2.2$ & $12.5 \pm 4.9$ & $141 \pm 8$ & $181 \pm 26$ & $1.8 \pm 0.5$ & $2.6 \pm 0.7$ \\
\hline smD & $137 \pm 8$ & $133 \pm 7$ & $27.5 \pm 2.4$ & $27.9 \pm 2.5$ & $521 \pm 86$ & $561 \pm 57$ & $5.5 \pm 0.9$ & $7.7 \pm 0.9$ \\
\hline smVG & $61 \pm 1$ & $64 \pm 4$ & $13.4 \pm 2.4$ & $12.4 \pm 0.7$ & $282 \pm 2$ & $366 \pm 22$ & $2.4 \pm 0.7$ & $2.8 \pm 0.4$ \\
\hline smVG2 & $29 \pm 3$ & $31 \pm 4$ & $6.1 \pm 0.7$ & $6.8 \pm 1.2$ & $111 \pm 28$ & $245 \pm 21$ & $2.3 \pm 0.3$ & $2.6 \pm 0.3$ \\
\hline $\mathrm{suHe}$ & $65 \pm 6$ & $99 \pm 10$ & $71.5 \pm 6.8$ & $41.8 \pm 4.6$ & $426 \pm 45$ & $476 \pm 100$ & $6.0 \pm 1.4$ & $7.7 \pm 2.3$ \\
\hline $\mathrm{BiSu}$ & $44 \pm 2$ & $46 \pm 1$ & $8.9 \pm 2.3$ & $10.3 \pm 1.8$ & $186 \pm 24$ & $228 \pm 14$ & $2.0 \pm 0.3$ & $2.2 \pm 0.3$ \\
\hline BeRo & $66 \pm 7$ & $81 \pm 2$ & $17.0 \pm 4.0$ & $19.5 \pm 2.5$ & $281 \pm 42$ & $333 \pm 73$ & $3.1 \pm 1.0$ & $4.0 \pm 0.7$ \\
\hline DöRo & $236 \pm 19$ & $223 \pm 25$ & $41.8 \pm 5.8$ & $41.1 \pm 4.3$ & $873 \pm 75$ & $1052 \pm 116$ & $13.9 \pm 2.0$ & $18.8 \pm 2.9$ \\
\hline FL2 & $124 \pm 18$ & $186 \pm 18$ & $44.1 \pm 4.6$ & $39.0 \pm 5.2$ & $738 \pm 85$ & $744 \pm 68$ & $9.8 \pm 2.3$ & $10.6 \pm 1.8$ \\
\hline FL6 & $173 \pm 21$ & $243 \pm 24$ & $46.0 \pm 4.8$ & $46.2 \pm 4.6$ & $1004 \pm 96$ & $986 \pm 29$ & $12.9 \pm 2.5$ & $15.7 \pm 2.0$ \\
\hline Gt1WS1 & - & $152 \pm 15$ & - & $43.6 \pm 4.4$ & - & $677 \pm 34$ & $3.6 \pm 1.0$ & $7.2 \pm 0.2$ \\
\hline Gt1WS2 & - & $65 \pm 7$ & - & $19.8 \pm 2.0$ & - & $636 \pm 32$ & $1.3 \pm 0.1$ & $2.8 \pm 1.0$ \\
\hline EF1WS & - & $88 \pm 15$ & - & $28.2 \pm 5.4$ & - & $333 \pm 5$ & $3.9 \pm 0.5$ & $4.1 \pm 0.5$ \\
\hline EF1MM & - & $16 \pm 4$ & - & $51.5 \pm 5.3$ & - & $28 \pm 1$ & $2.7 \pm 1.4$ & $5.0 \pm 1.3$ \\
\hline EF1GS & - & $172 \pm 18$ & - & $41.3 \pm 4.2$ & - & $549 \pm 27$ & $8.2 \pm 1.4$ & $8.7 \pm 2.6$ \\
\hline EF1OK & - & $149 \pm 15$ & - & $35.2 \pm 4.0$ & - & $334 \pm 17$ & $6.0 \pm 1.7$ & $7.7 \pm 2.0$ \\
\hline EF1UKK & - & $132 \pm 19$ & - & $49.7 \pm 1.4$ & - & $320 \pm 16$ & $6.2 \pm 2.1$ & $7.4 \pm 1.8$ \\
\hline EF1KO & - & $160 \pm 19$ & - & $55.8 \pm 1.8$ & - & $584 \pm 65$ & $7.0 \pm 1.6$ & $7.4 \pm 1.9$ \\
\hline EF1HS & - & $122 \pm 11$ & - & $30.2 \pm 3.1$ & - & $235 \pm 12$ & $7.3 \pm 1.5$ & $6.3 \pm 1.7$ \\
\hline Gt1DU1 & - & $147 \pm 23$ & - & $33.0 \pm 0.3$ & - & $635 \pm 19$ & $4.5 \pm 1.6$ & $12.1 \pm 3.4$ \\
\hline Gt1DU2 & - & $107 \pm 4$ & - & $25.4 \pm 3.2$ & - & $541 \pm 27$ & $5.7 \pm 0.4$ & $6.5 \pm 1.5$ \\
\hline Gt1DU3 & - & $164 \pm 20$ & - & $37.0 \pm 5.9$ & - & $907 \pm 45$ & $9.3 \pm 2.7$ & $10.2 \pm 0.7$ \\
\hline Gt1DW & - & $141 \pm 12$ & - & $35.9 \pm 3.5$ & - & $304 \pm 49$ & $6.1 \pm 2.1$ & $11.2 \pm 3.0$ \\
\hline Gt1VS1 & - & $128 \pm 28$ & - & $37.2 \pm 9.6$ & - & $342 \pm 32$ & $3.6 \pm 1.5$ & $7.9 \pm 1.6$ \\
\hline Gt1VS2 & - & $187 \pm 15$ & - & $35.1 \pm 2.8$ & - & $707 \pm 35$ & $7.0 \pm 1.7$ & $8.3 \pm 1.2$ \\
\hline
\end{tabular}

SD, Standard deviation; UCS, uniaxial compressive strength; $E_{\mathrm{S}}$, static Young's modulus; $W$, destruction work; $T_{0}$, indirect tensile strength. 

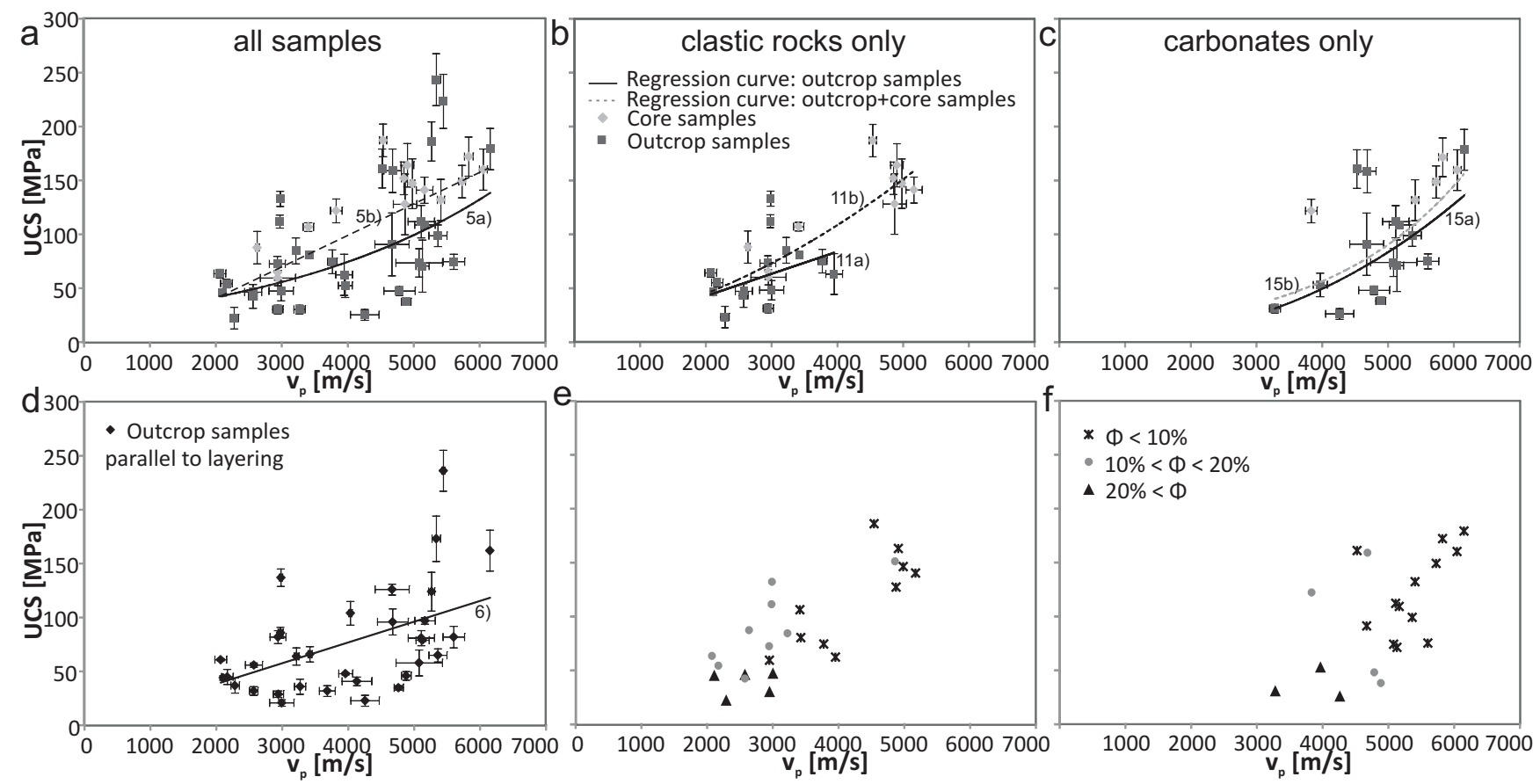

Figure 3. $v_{\mathrm{p}}$ vs. UCS for specimens taken perpendicular to bedding for outcrop and core samples separately for (a) all samples $(n=49)$, (b) only clastic rock samples $(n=24)$ and (c) only carbonate samples $(n=20)$; (d) $v_{\mathrm{p}}$ vs. UCS for all specimens taken parallel to bedding $(n=33)$; regression curves shown for both outcrop and core samples and outcrop samples only; for regression equations see Table 5. Error bars stand for standard deviations of all measurements of every sample (Tables 2-4). (e-f) $v_{\mathrm{p}}$ vs. UCS for low-, medium- and high-porosity samples of clastic rocks (e) and carbonates (f).

of both $\Phi$ and $\rho$ values. Though clastic core samples plot far above the regression curve of UCS- $\Phi$ of outcrop samples this is mainly based on the lack of outcrop samples with low porosities (Fig. 2b). For UCS- $\rho$, however, core samples plot along an extension of the regression curve for outcrop data (Fig. 2f). Data therefore show that, if core samples are included, the best fit regression curve is similar to the one with outcrop data only.

\subsection{2 $P$ wave velocity}

Many studies show that UCS correlates positively with $v_{\mathrm{p}}$ and travel time, respectively (Freyburg, 1972; McNally, 1987; Kahraman, 2001; Sharma and Singh, 2008). $v_{\mathrm{p}}$ is one parameter determined easily with borehole acoustic logs (e.g. Fricke and Schön, 1999; Rider and Kennedy, 2011) and it may be relevant for the geomechanical model validation and logging-while-drilling.

UCS $-v_{\mathrm{p}}$ data show a wide scatter for all samples both perpendicular and parallel to bedding (Fig. 3a, d). The coefficients of determination are rather poor for both outcrop samples only and core samples included (Table 5). However, there are only small differences between best fit curves for outcrop samples only and core samples included. Especially for carbonates, the regression curve differs only slightly when core samples are included (Fig. 3c). There is some de- viation for clastic rocks due to lacking low-porosity outcrop samples (Fig. 3b). The coefficient of determination is yet considerably higher if core samples are included (Eq. 11b).

There are conspicuous interdependencies between UCS, $v_{\mathrm{p}}$ and porosity for both clastic rocks and carbonates. Highporosity clastic and carbonate rocks have the lowest UCS and $v_{\mathrm{p}}$ values, and low-porosity samples have the highest values (Fig. 3e, f). If porosities are plotted vs. $P$ wave velocities (Fig. 4) there is a clear linear relationship for carbonates at higher $v_{\mathrm{p}}$ values. The mineralogical composition of clastic rock samples is more heterogeneous compared with carbonate samples reflected in a wider scatter of $v_{\mathrm{p}}$ values at lower UCS values. $v_{\mathrm{p}}$ values strongly depend on mineral composition due to the minerals' different elastic wave velocities (e.g. Gebrande et al., 1982). Sandstones' main component quartz has a considerably lower $v_{\mathrm{p}}$ than calcite, the main component of carbonates. $v_{\mathrm{p}}$ of dolomite is lower, too. Consequently, two samples with dolomitic composition (EL1, EL3) plot above the regression curve of carbonates (Fig. 3c).

\subsubsection{Young's modulus}

Former studies showed that, in most cases, there is a strong correlation between $E_{\mathrm{S}}$ and UCS (Sachpazis, 1990; Aggistalis et al., 1996; Palchik, 1999; Dinçer et al., 2004). Our data, shown in Fig. 5, are in good agreement with 
Table 5. Summarised results of statistical analyses for the correlation of UCS with different parameters of both outcrop and core samples and outcrop samples only with coefficients of determination $R^{2}$.

\begin{tabular}{|c|c|c|c|c|c|c|}
\hline & \multicolumn{3}{|c|}{ Outcrop samples only } & \multicolumn{3}{|c|}{ Outcrop and core samples } \\
\hline & Eq. & $\mathrm{UCS}[\mathrm{MPa}]$ & $R^{2}$ & Eq. & UCS [MPa] & $R^{2}$ \\
\hline \multirow[t]{8}{*}{ All samples } & (1a) & $-28.6 \ln (\Phi)+144.2$ & 0.675 & (1b) & $151.95 \mathrm{e}^{-0.051 \Phi}$ & 0.526 \\
\hline & $(2)^{*}$ & $-22.2 \ln (\Phi)+115.9$ & 0.558 & & & \\
\hline & (3a) & $0.775 \rho^{5.16}$ & 0.571 & (3b) & $1.285 \rho^{4.66}$ & 0.520 \\
\hline & $(4)^{*}$ & $0.568 \mathrm{e}^{1.943 \rho}$ & 0.498 & & & \\
\hline & (5a) & $23.763 \mathrm{e}^{0.0003 v_{\mathrm{p}}}$ & 0.314 & $(5 b)$ & $0.029 v_{\mathrm{p}}-19.09$ & 0.405 \\
\hline & $(6)^{*}$ & $0.019 v_{\mathrm{p}}$ & 0.269 & & & \\
\hline & (7a) & $2.474 E_{\mathrm{s}}^{1.102}$ & 0.590 & (7b) & $3.335 E_{\mathrm{s}}^{1.008}$ & 0.686 \\
\hline & $(8)^{*}$ & $7.538 E_{\mathrm{s}}^{0.698}$ & 0.639 & & & \\
\hline \multirow[t]{4}{*}{ Sandstones } & (9a) & $110.73 \mathrm{e}^{-0.037 \Phi}$ & 0.206 & $(9 b)$ & $152.6 \mathrm{e}^{-0.053 \Phi}$ & 0.608 \\
\hline & (10a) & $3.453 \rho^{3.427}$ & 0.266 & (10b) & $2.245 \rho^{4.0132}$ & 0.493 \\
\hline & (11a) & $0.025 v_{\mathrm{p}}^{0.980}$ & 0.185 & (11b) & $4 \times 10^{-6} v_{\mathrm{p}}^{2}+0.009 v_{\mathrm{p}}+11.5$ & 0.651 \\
\hline & (12a) & $4.319 E_{\mathrm{s}}^{0.944}$ & 0.682 & (12b) & $3.364 E_{\mathrm{s}}^{1.035}$ & 0.822 \\
\hline \multirow[t]{6}{*}{ Carbonates } & (13a) & $129.95 \mathrm{e}^{-0.051 \Phi}$ & 0.517 & (13b) & $137.08 \mathrm{e}^{-0.043 \Phi}$ & 0.390 \\
\hline & (14a) & $0.319 \rho^{5.953}$ & 0.708 & (14b) & $1.116 \rho^{4.741}$ & 0.476 \\
\hline & $(15 a)$ & $2 \times 10^{-7} v_{\mathrm{p}}^{2.351}$ & 0.351 & $(15 b)$ & $8.535 \mathrm{e}^{0.0005 v_{\mathrm{p}}}$ & 0.360 \\
\hline & (16a) & $1.928 E_{\mathrm{s}}^{1.098}$ & 0.576 & (16b) & $1.783 E_{\mathrm{s}}^{1.138}$ & 0.616 \\
\hline & \multicolumn{3}{|c|}{ Outcrop samples only } & \multicolumn{3}{|c|}{ Outcrop and core samples } \\
\hline & Eq. & Regression function & $R^{2}$ & Eq. & Regression function & $R^{2}$ \\
\hline \multirow[t]{4}{*}{ All samples } & (17a) & $W=3.953 \mathrm{UCS}$ & 0.824 & (17b) & $W=5.954 \mathrm{UCS}^{0.9023}$ & 0.678 \\
\hline & $(18)^{*}$ & $W=3.026 \mathrm{UCS}^{1.07}$ & 0.816 & & & \\
\hline & (19a) & $T_{0}=0.0002 \mathrm{UCS}^{2}+0.023 \mathrm{UCS}+2.30$ & 0.861 & $(19 b)$ & $T_{0}=0.0002 \mathrm{UCS}^{2}+0.02 \mathrm{UCS}+2.35$ & 0.787 \\
\hline & $(20)^{*}$ & $T_{0}=3 \times 10^{-5} \mathrm{UCS}^{2}+0.047 \mathrm{UCS}+1.01$ & 0.797 & & & \\
\hline \multirow[t]{2}{*}{ Sandstones } & (21a) & $W=2.867 \mathrm{UCS}^{1.102}$ & 0.729 & (21b) & $W=7.164 \mathrm{UCS}^{0.889}$ & 0.611 \\
\hline & (22a) & $T_{0}=0.0002 \mathrm{UCS}^{2}+0.0065 \mathrm{UCS}+2.46$ & 0.581 & (22b) & $T_{0}=1.9125 \mathrm{e}^{0.01 \mathrm{UCS}}$ & 0.758 \\
\hline \multirow{2}{*}{ Carbonates } & (23a) & $W=3.714 \mathrm{UCS}^{0.98}$ & 0.804 & (23b) & $W=4.851 \mathrm{UCS}^{0.906}$ & 0.769 \\
\hline & $(24 a)$ & $T_{0}=3.79 \ln (\mathrm{UCS})-9.997$ & 0.862 & (24b) & $T_{0}=0.407 \mathrm{UCS}^{0.609}$ & 0.817 \\
\hline
\end{tabular}

* Parallel to bedding.

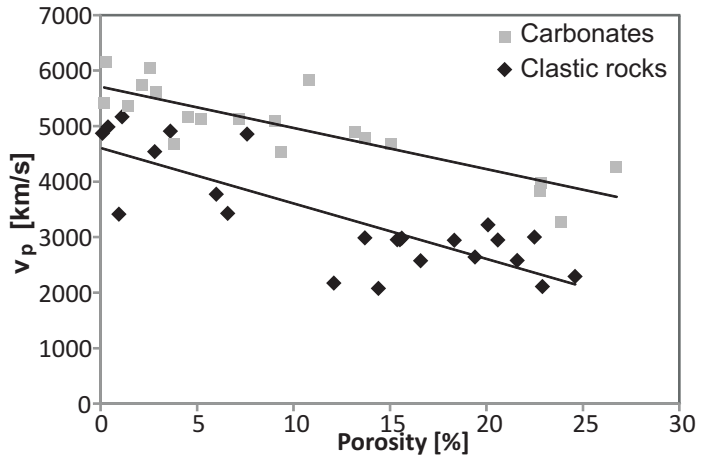

Figure 4. Porosity vs. $v_{\mathrm{p}}$ for carbonates and clastic rocks (see key) with linear regression lines. these studies, especially for the lithologically separated plots (Fig. 5b, c). Coefficients of determination are in most cases high. To better analyse the statistical significance of the developed regression functions for outcrop samples, $90 \%$ confidence and prediction bands are added.

If all lithologies are plotted together, there is a certain scatter of data both perpendicular and parallel to bedding reflected in wide $90 \%$ prediction bands (Fig. 5a, d). Parallel to bedding the $E_{\mathrm{s}}$ values tend to be slightly higher than if perpendicular. For small UCS and $E_{\mathrm{S}}$ values the relationship between the parameters is excellent, and with higher values the scatter increases considerably. The core samples comply with the data of outcrop samples. When core results are included, the quality of regression analysis fit is even improved and is demonstrated by a higher coefficient of determination (Fig. 5a; Table 5).

If sandstone samples are plotted separately, the coefficient of determination is high and confidence and prediction bands, respectively, are narrow (Table 5; Fig. 5b). It has 

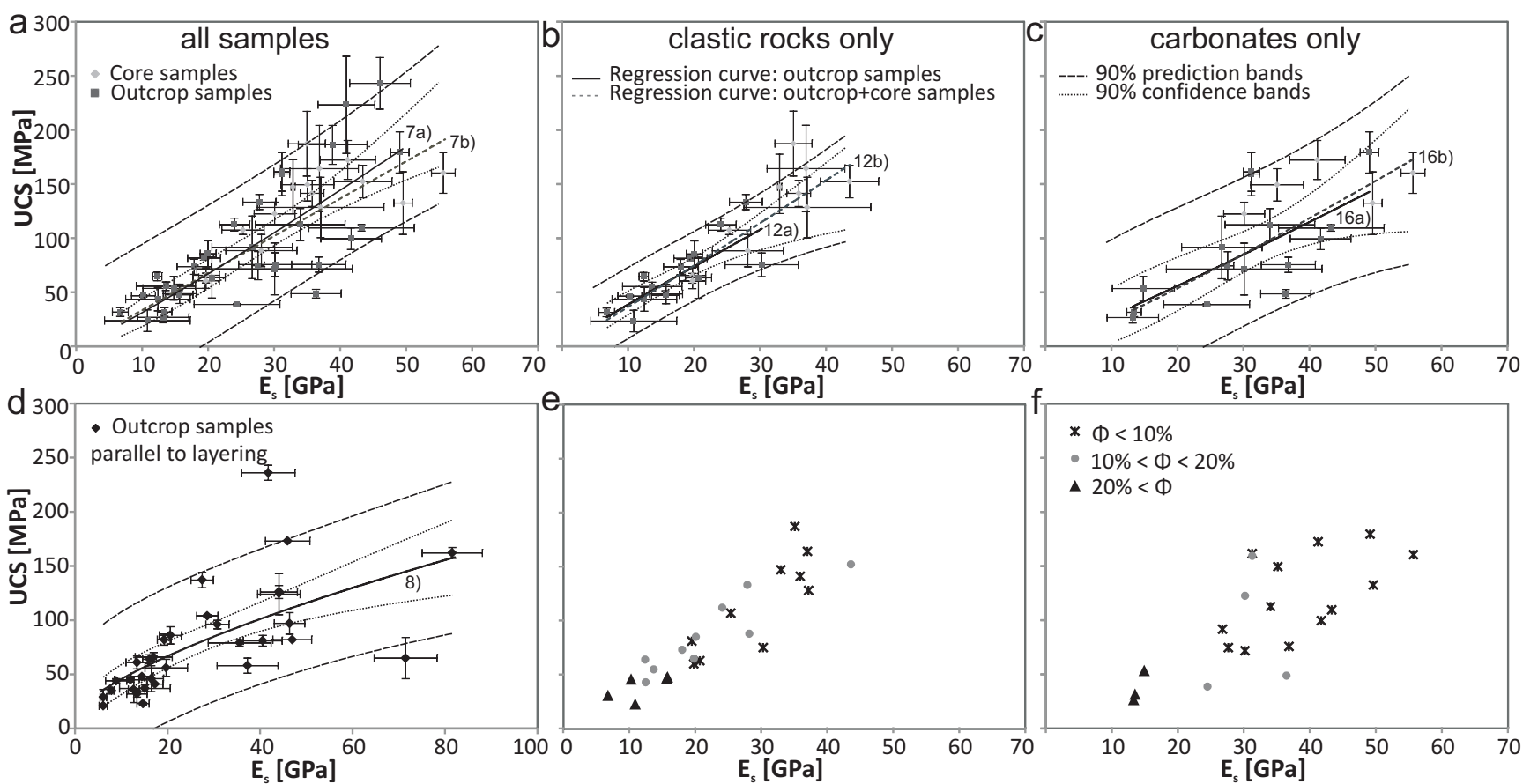

Figure 5. $E_{\mathrm{S}}$ vs. UCS for specimens taken perpendicular to bedding for outcrop and core samples separately for $(\mathbf{a})$ all samples $(n=49)$, (b) only clastic rock samples $(n=24)$ and (c) only carbonate samples $(n=19)$; (d) $E_{\mathrm{S}}$ vs. UCS for all specimens taken parallel to bedding $(n=33)$. Regression curves shown for both outcrop and core samples and outcrop samples only; $90 \%$ prediction and confidence bands are included; for regression equations see Table 5. Error bars stand for standard deviations of all measurements of every sample (Table 4). (e, f) $E_{\mathrm{S}}$ vs. UCS for low-, medium- and high-porosity samples of clastic rocks (e) and carbonates (f).

to be considered that the sampled carbonates are both matrix and sparry limestones with varying amount of bioclasts (cf. Tables 2, 3). These more-heterogeneous compositions of carbonate samples are reflected in statistically less satisfactory results $\left(R^{2}=0.576\right.$; Table 5$)$ with wider prediction and confidence bands (Fig. 5c). The increase of the regression curve is lower than for sandstone samples; that is, a carbonate sample is expected to have a higher $E_{\mathrm{S}}$ value than a sandstone sample of similar UCS. For both, sandstones and carbonates, equivalent core samples match the scatter of outcrop data well and lie within the $90 \%$ prediction bands. There are only minor changes of regression curves if core samples are included (Fig. 5b, c).

There is a known relationship between porosity and Young's modulus of rocks (e.g. Rajabzadeh et al., 2012). Therefore, we redraw the UCS- $E_{\mathrm{S}}$ data of sandstones and carbonates with different marks for low-, medium- and highporosity rocks (Fig. 5e, f). Sandstones and carbonates with high porosities have the lowest UCS and $E_{\mathrm{S}}$ values; the differences between medium- and low-porosity rocks are less pronounced. Both porosity classes include medium UCS and $E_{\mathrm{S}}$ values as well as high values.

\subsection{Deriving rock properties from UCS}

\subsubsection{Destruction work}

The destruction work is an important parameter for dimensioning and planning of drilling projects and correlates with drilling efficiency (Thuro, 1997). Rocks which strongly deform while loading have high destruction-work values because for specimen failure more energy is needed. The destruction work, calculated as the area below the stress-strain curve of the uniaxial compression test, is plotted against UCS of the different samples (Fig. 6).

Regression analyses show that power-law functions fit best in most cases, and coefficients of determination are rather high in all cases. To analyse the statistical significance, $90 \%$ confidence and prediction bands are added.

For outcrop samples parallel and perpendicular to bedding, the fit is excellent with narrow bands (Fig. 6a, d; Table 5). There are, however, clear lithological differences of the destruction-work values. For carbonates, core samples show a considerable deviation from the regression function of outcrop data more to lower $W$ values for similar UCS (Fig. 6c). For sandstones, core samples show a wider scatter, in some cases even beyond the $90 \%$ prediction bands of outcrop samples (Fig. 6b). The slope for clastic rock samples is considerably steeper than that of carbonate rocks (Fig. 6c). That is, more energy is needed to destruct a sandstone sample 

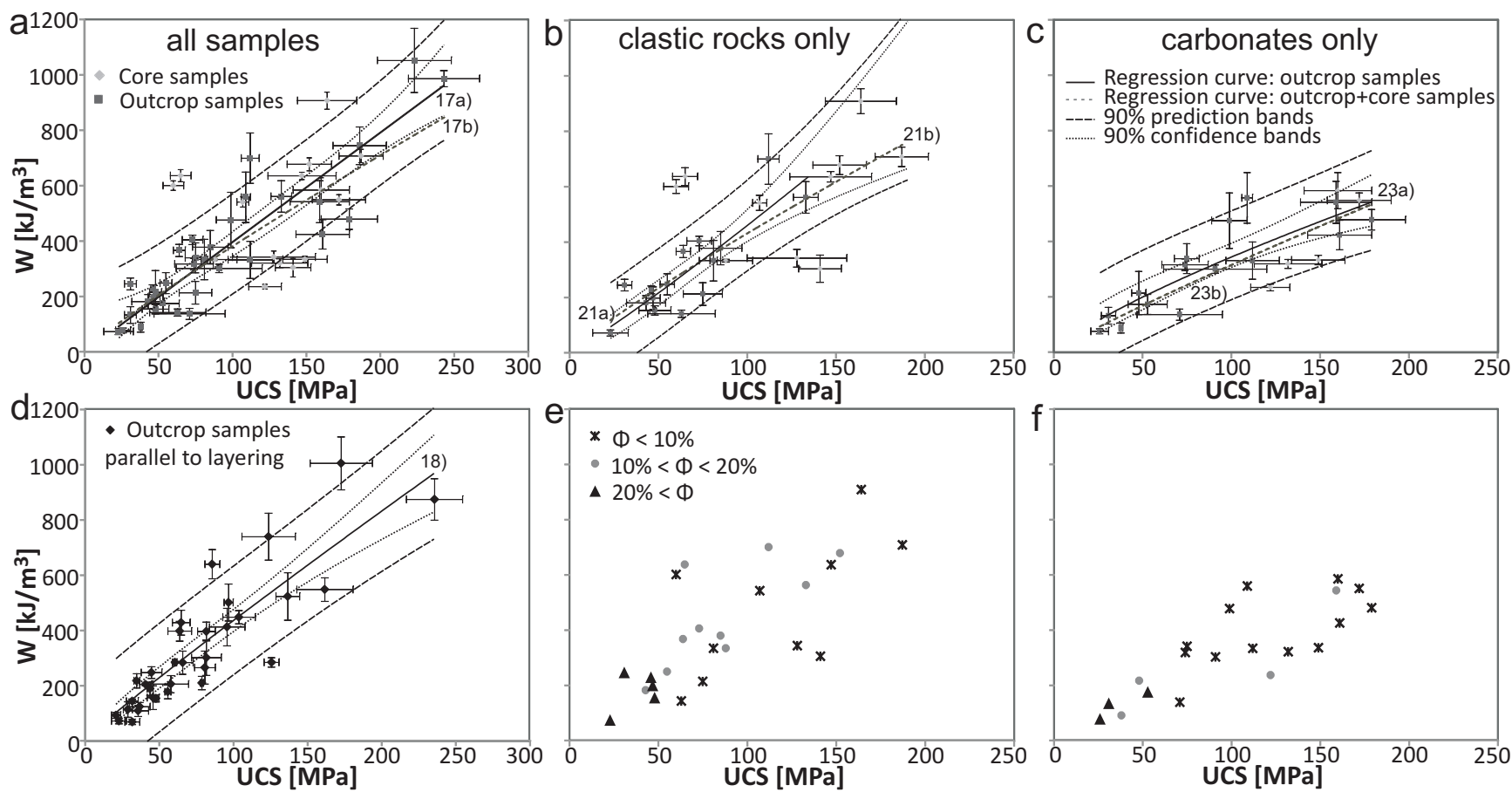

Figure 6. UCS vs. $W$ for specimens taken perpendicular to bedding for outcrop and core samples separately for (a) all samples $(n=49)$, (b) only clastic rock samples $(n=24)$ and (c) only carbonate samples $(n=18)$; (d) UCS vs. $W$ for all specimens taken parallel to bedding $(n=33)$. Regression curves shown for both outcrop and core samples and outcrop samples only; $90 \%$ prediction and confidence bands are included; for regression equations see Table 5. Error bars stand for standard deviations of all measurements of every sample (Table 4). (e-f) UCS vs. $W$ for low-, medium- and high-porosity samples of clastic rocks (e) and carbonates (f).

than a carbonate sample of the same UCS value. From that we infer that sandstone samples receive more deformation at the same applied stress than carbonate samples.

In the same way as we did for UCS- $E_{\mathrm{S}}$ values (Fig. $5 \mathrm{e}$, f), UCS- $W$ data of sandstones and carbonates with low-, medium- and high-porosity rocks are plotted separately (Fig. 6e, f). Also in this case, sandstones and carbonates with high porosities have the lowest UCS and $W$ values; the differences between medium- and low-porosity rocks are less clear. For carbonate samples, however, we recognise that low-porosity samples tend to have higher UCS and $W$ values than high-porosity samples (Fig. 6f).

\subsubsection{Indirect tensile strength}

For rocks, there is a known correlation between compressive and tensile strength with a factor of approximately 10 between these two parameters (e.g. Hobbs, 1964; Lockner, 1995). Our results are in good accordance; coefficients of determination are high in all cases with very narrow confidence and prediction bands. Overall, the values of core samples are similar to the values of outcrop samples and plot within the $90 \%$ prediction bands. Both regression functions, developed for clastic rocks, are very similar, and core results fit well within the scatter that is quite similar to outcrop results
(Fig. 7b; Eqs. 22a, b). For carbonates, the equivalent core samples also plot within the $90 \%$ prediction bands (Fig. 7c).

However, there are clear lithological differences in the indirect tensile strength values of the outcrop samples (Fig. 7b, c). For low UCS, $T_{0}$ values of clastic rock samples are lower than those of carbonates; for high UCS, however, the increase of $T_{0}$ values is less for carbonates, leading to higher values of clastic rock samples.

We plot UCS $-T_{0}$ data of sandstones and carbonates with low-, medium- and high-porosity rocks (Fig. 7e, f; see key). This empirical relation also shows that high-porosity samples of clastic rocks and carbonates have the lowest UCS and $T_{0}$ values; the differences between medium and lowporosity rocks are less clear. In contrast to the UCS- $W$ relation (Fig. 6) where carbonates tend to have higher values, we recognise that in this case low-porosity sandstone samples tend to have higher UCS and $T_{0}$ values.

\section{Discussion}

\subsection{Applicability of empirical relations to predict in situ rock properties}

A comparison of empirical relations, determined from outcrop samples only, with properties of core samples gives information on parameter changes due to load removal and 

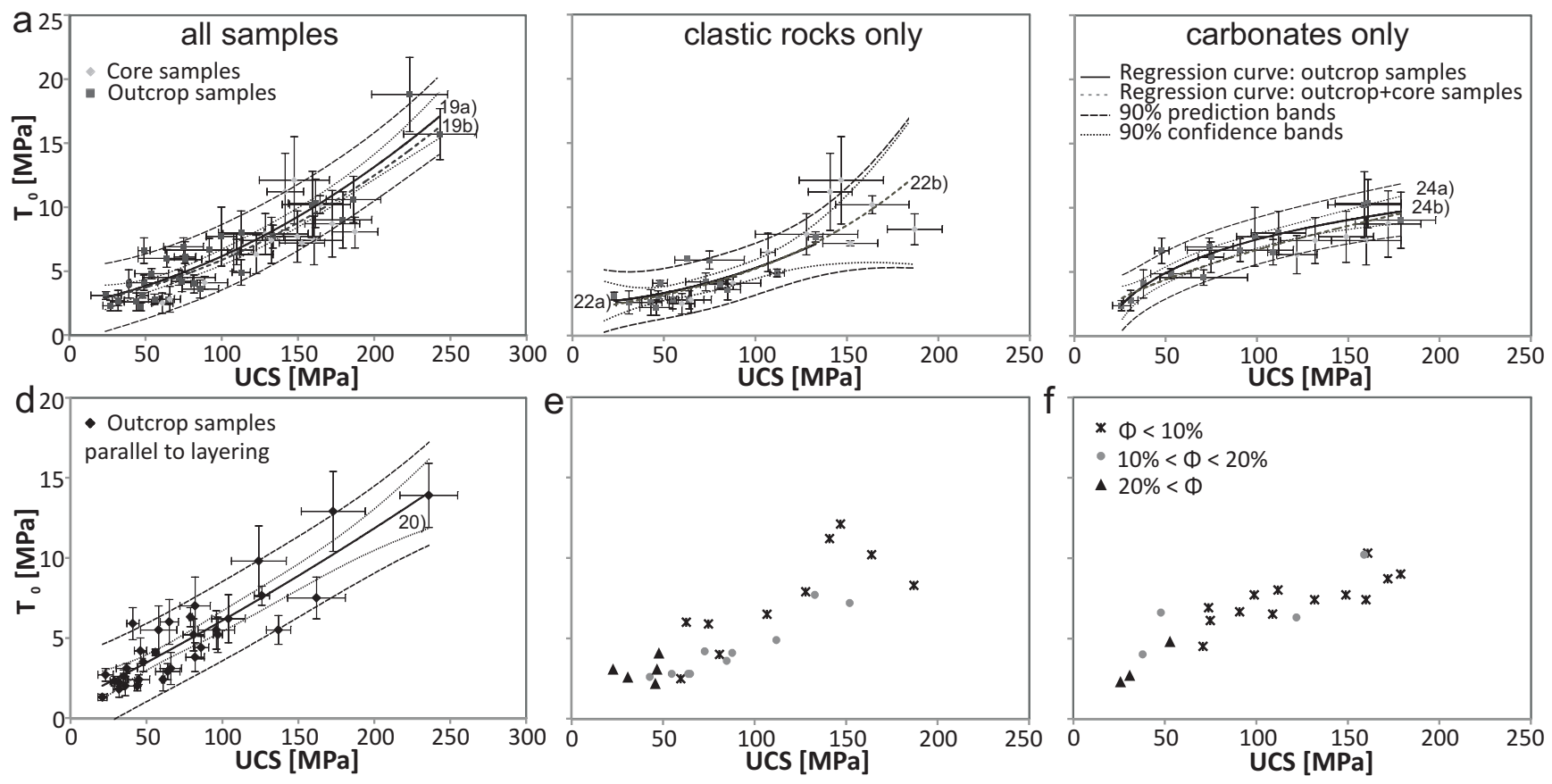

Figure 7. UCS vs. $T_{0}$ for specimens taken perpendicular to bedding for outcrop and core samples separately for (a) all samples $(n=49)$, (b) only clastic rock samples $(n=24)$ and (c) only carbonate samples $(n=18)$; (d) UCS vs. $T_{0}$ for all specimens taken parallel to bedding $(n=33)$. Regression curves shown for both outcrop and core samples and outcrop samples only; $90 \%$ prediction and confidence bands are included; for regression equations see Table 5. Error bars stand for standard deviations of all measurements of every sample (Table 4). (e-f) UCS vs. $T_{0}$ for low-, medium- and high-porosity samples of clastic rocks (e) and carbonates (f).

beginning of alteration. We found that the developed empirical relations with or without core samples are quite similar for all analysed parameters (cf. Sect. 5, Table 5). Simply, core samples have similar or only slightly higher values than outcrop samples. That is, the ratios of UCS with the considered parameters do not change considerably. Based on these findings it is assumed that these parameter-UCS ratios remain unaffected by unloading. Only the destruction work shows some divergence between outcrop and core samples. For carbonates with high UCS, destruction-work values of core samples tend to be lower than those of outcrop samples with comparable UCS resulting in a steeper regression function for outcrop samples only (Fig. 6c). That is, for the destruction of core samples less energy is needed than for outcrop samples. This may be caused by higher porosities of outcrop samples where more energy can be absorbed by pore-space destruction before brittle failure occurs. The destruction work, measured in laboratory, correlates with the in situ drillability of rocks (Thuro, 1997). Therefore, the destruction work, measured in laboratory, is strongly related to field-work efforts.

The UCS $-E_{\mathrm{S}}$ relationship indicates that clastic and carbonate rocks including their core equivalents show different behaviour. A carbonate rock is expected to have a higher $E_{\mathrm{S}}$ compared with a clastic rock of the same UCS (Fig. 5). The intensity of deformation depends on the rock strength, the stresses applied and the time over which the stresses are acting and accumulating. It is known that carbonate rocks react differently to stresses than clastic rocks (e.g. Lockner, 1995; Jaeger et al., 2007). On long-term-stress applications clastic rocks may receive more brittle deformation than carbonate rocks due to pressure-solution and slip-folding processes which are typical phenomena in carbonates (Fossen, 2010). These are deformation processes which act on a longer timescale. At drilling operations, however, there is only a short-term-stress application on the rock mass similarly to laboratory experiments. That is, the UCS $-E$ relationship is developed for a similar timescale as the goal of this study, namely drilling applications, and not for long-termdeformation processes.

All data in this study were determined in laboratory measurements of dry rock specimens. Applying the results to in situ conditions is non-trivial for some parameters because rocks at depth are loaded by overburden and confining pressures and are commonly saturated with fluids. Saturation and pressures have strong effects on some of the described parameters.

The compressional wave velocity is one parameter which can be determined easily by using a borehole acoustic log. It has to be taken into account that $v_{\mathrm{p}}$ measurements in boreholes comprise a larger volume which may include fractures and are obtained with different frequencies than laboratory 
measurements. Therefore, in most cases, saturated samples, measured in laboratory, give higher $v_{\mathrm{p}}$ values than in situ rocks determined from well logs (e.g. Popp and Kern, 1994; Zamora et al., 1994). Laboratory measurements of dry specimens will give lower velocities than those of fully saturated samples (Nur and Simmons, 1969). Kahraman (2007) showed that for sedimentary rocks there is a strong linear correlation between $P$ wave velocities of dry $v_{\mathrm{p}}^{\mathrm{d}}$ and saturated rocks $v_{\mathrm{p}}^{\mathrm{w}}$. Most rocks show significant trends of UCS reduction with increasing degree of saturation (Shakoor and Barefield, 2009; Karakul and Ulusay, 2013). For Miocene limestones, there is a reduction of UCS and $T_{0}$ values with increasing saturation (Vásárhelyi, 2005). Similarly, Baud et al. (2000) showed that there is a weakening effect of water on sandstone. Triaxial tests have shown that compressive strength and Young's modulus of rocks positively correlate with confining pressure (Nur and Simmons, 1969; You, 2003; Zoback, 2007).

All laboratory measurements have been carried out on high-quality samples where discontinuities such as fractures are absent. In situ rocks, in contrast, typically include fractures. That is, UCS and $E_{\mathrm{S}}$ values measured with laboratory tests tend to be higher than those measured in situ (Priest, 1993; Huang et al., 1995). The presented data of Young's modulus were determined with uniaxial compressive tests, which give static Young's modulus values referring to fracture propagation (cf., Section 1; Jaeger et al., 2007). In boreholes, from acoustic logs, dynamic Young's moduli are obtained (Zoback, 2007; Rider and Kennedy, 2011). The comparison of dynamic and static Young's moduli is complicated. Discontinuities such as fractures have different effects on static measurements of Young's modulus and $P$ wave propagation. Martínez-Martínez et al. (2012), for example, showed that, for carbonate rocks, there is only a poor linear relationship which can be corrected by using $v_{\mathrm{p}}$ and Poisson's ratio.

This shows that transfer to in situ conditions has to be considered carefully for each parameter individually.

For validation purposes, it is advisable to apply the developed equations on logging data of wellbores in the NWGB for UCS calculation. It would then be possible to compare the calculated UCS values with the actual UCS values measured with cores of the same wellbore (cf., Vogt et al., 2012). The estimation of rock strength is not only possible with empirical relations as presented in this study but also with micromechanical methods (e.g, Sammis and Ashby, 1986; Zhu et al., 2011), which are powerful tools to understand failure processes in rock. To build a geomechanical model before starting the drilling operation, such micromechanical methods may be a good supplemental option when using data from adjacent wellbores.

\subsection{Comparison with previous studies}

Many empirical relations between UCS and other parameters were developed. In Table 6, selected equations are presented. None of these relations, however, refer to the NWGB. These functions fit best for the geological situation the analysed samples belong to and are only valid for the defined range of parameter values (cf. Fig. 8). In most cases, the functions relate to a specific lithology.

The presented regression analyses show that coefficients of determination of the regression curves for carbonates have, in most cases, smaller values compared with sandstone samples. Carbonate samples from the NWGB include sparry and matrix limestones, bioclast-rich limestones, oolites, marls, and dense and porous limestones (cf. Tables 2, 3 ). This means that the lithology of sampled carbonates is much more variable than that of sandstones. This may be one reason for the wider range of mechanical and physical data and the poorer relations of UCS- $E_{\mathrm{S}}$ (Eqs. 12b, 16b), UCS$v_{\mathrm{p}}$ (Eqs. 11b, 15b), and UCS- $\Phi$ (Eqs. 9b, 13b). In former studies on limestones (e.g. McNally, 1987; Sachpazis, 1990; Bradford et al., 1998; Chang et al., 2006) the lithology, for which the empirical relation was developed, is specified. Accordingly, the presented relationships are more trustworthy if they refer to a specific lithology (cf. Eqs. 9-16, 21-24). If only general assumptions of UCS values are needed (e.g. from well logs of heterogeneous stratifications) or the lithology of the respective wellbore section cannot be defined precisely, it appears to be better to apply the empirical relations generated for all samples (Eqs. 1-8, 17-20).

To compare the regression functions, developed in this study, with the relations of previous studies we use a graphic representation considering the range of parameter values for which the relations were developed (Table 6; Fig. 8). Differences between the functions are depicted. For clastic rocks, there are significant variations for small porosities (Fig. 8a.1). Vernik et al. (1993; Eq. 25) predict much higher UCS for low-porosity sandstones $(\Phi<15 \%)$ and lower UCS for high-porosity sandstones $(\Phi>25 \%)$ than Eqs. (9a) and (9b). They, however, determined UCS values from triaxial testing, which gives higher UCS values than uniaxial compressive strength measurements (cf. Zoback, 2007). The effects of small discontinuities on rock strength are smaller when confining pressure is applied.

For carbonate rock samples, however, the calculated regression functions (Eqs. 13a, b) fit perfectly well with previous studies (Fig. 8a.2). Only for high-porosity carbonate rocks $(\Phi>15 \%)$ are the smallest variations from Eq. (30) in the range of $10 \mathrm{MPa}$ for UCS.

The errors of the empirical relations between UCS $-v_{\mathrm{p}}$ and UCS- $\Delta t$, respectively, are high for all studies (cf. Table 5). The determined regression functions of previous studies are, however, quite similar to Eq. (11b) for clastic rocks (Fig. 8b). The UCS $-v_{\mathrm{p}}$ relation of Freyburg (1972; Eq. 34) is in good accordance with our results. The data relate to sandstones 


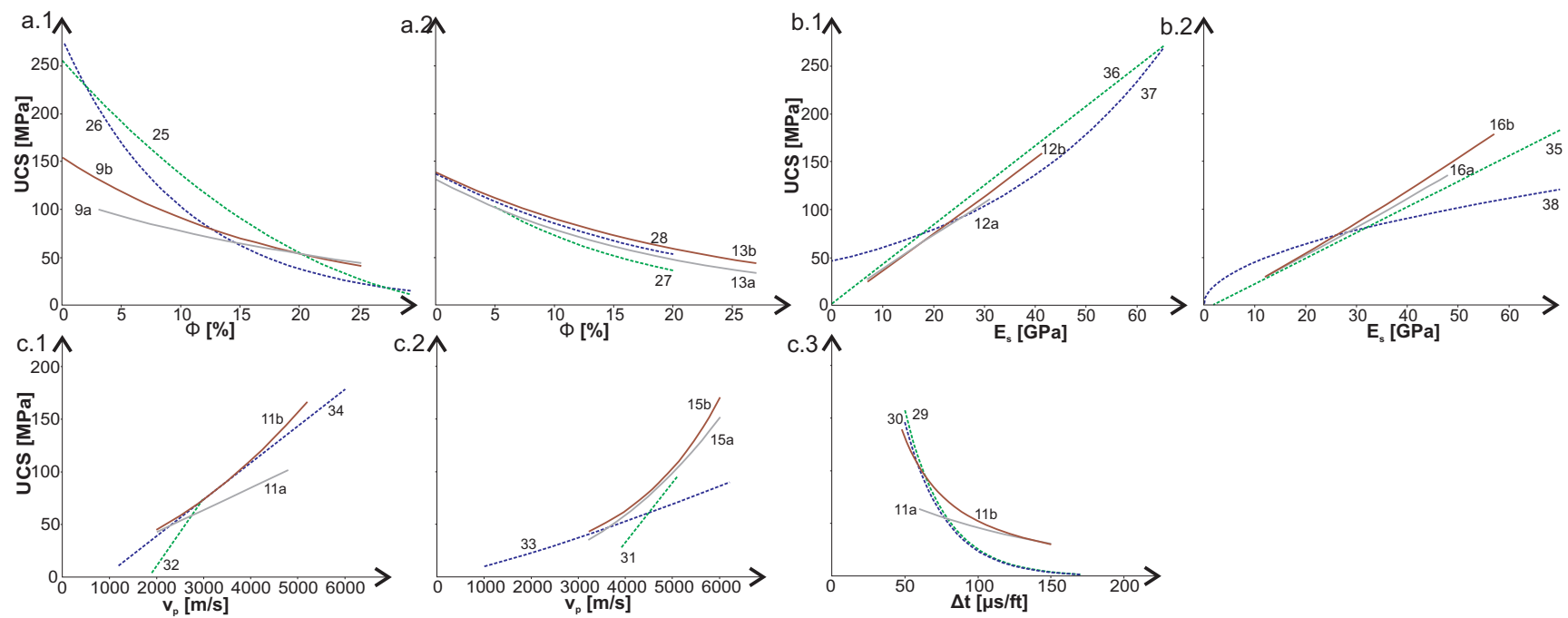

Figure 8. Correlations between UCS and the parameters (a) porosity, (b) $E_{\mathrm{S}}$ and (c) $v_{\mathrm{p}}$ separately for clastic rocks and carbonates; correlations from this study and those published by other authors (equation numbers shown) consider the range of parameter values for which the functions are valid.

Table 6. Correlations between UCS and the parameters porosity, $P$ wave velocity, travel time and Young's modulus reported by other authors.

\begin{tabular}{|c|c|c|c|c|}
\hline Eq. & Parameter & $\mathrm{UCS} 2: 1[\mathrm{MPa}]$ & Rock type & Reference \\
\hline (25) & $\Phi$ & $254(1-0.027 \Phi)[\Phi$ in \%] & Clastic rocks & Vernik et al. (1993) \\
\hline (26) & & $277 \mathrm{e}^{-0.1 \Phi}[\Phi$ in \%] & Sandstones $(0.2<\Phi<33 \%)$ & Chang et al. (2006) \\
\hline (27) & & $143.8 \mathrm{e}^{-0.0695 \Phi}[\Phi$ in $\%]$ & High UCS limestones $(5<\Phi<20 \%)$ & Chang et al. (2006) \\
\hline (28) & & $135.9 \mathrm{e}^{-48 \Phi}[\Phi$ in $\%]$ & High UCS limestones $(0<\Phi<20 \%)$ & Chang et al. (2006) \\
\hline (29) & $v_{\mathrm{p}} / \Delta t$ & $1277 \mathrm{e}^{-0.036 \Delta t}\left[\Delta t\right.$ in $\left.\mu \mathrm{st}^{-1}\right]$ & Sandstones & McNally (1987) \\
\hline (30) & & $1174 \mathrm{e}^{-0.0358 \Delta t}\left[\Delta t\right.$ in $\left.\mu \mathrm{ft}^{-1}\right]$ & Clastic rocks & McNally (1987) \\
\hline (31) & & $56.71 v_{\mathrm{p}}-192.93\left[v_{\mathrm{p}}\right.$ in $\left.\mathrm{km} \mathrm{s}^{-1}\right]$ & Limestones, clastic rocks $\left(3.9<v_{\mathrm{p}}<5.2 \mathrm{~km} \mathrm{~s}^{-1}\right)$ & Çobanoğlu and Çelik (2008) \\
\hline (32) & & $0.0642 v_{\mathrm{p}}-117.99\left[v_{\mathrm{p}}\right.$ in $\left.\mathrm{ms}^{-1}\right]$ & Different kinds of rock $\left(1.8<v_{\mathrm{p}}<3.0 \mathrm{~km} \mathrm{~s}^{-1}\right)$ & Sharma and Singh (2008) \\
\hline (33) & & $9.95 v_{\mathrm{p}}^{1.21}\left[v_{\mathrm{p}}\right.$ in $\left.\mathrm{km} \mathrm{s}^{-1}\right]$ & Different kinds of rock $\left(1<v_{\mathrm{p}}<6.3 \mathrm{~km} \mathrm{~s}^{-1}\right)$ & Kahraman (2001) \\
\hline (34) & & $0.035 v_{\mathrm{p}}-31.5\left[v_{\mathrm{p}}\right.$ in $\left.\mathrm{m} \mathrm{s}^{-1}\right]$ & Sandstones & Freyburg (1972) \\
\hline (35) & $E_{\mathrm{S}} / E$ & $2.667 E_{\mathrm{S}}-4.479\left[E_{\mathrm{S}}\right.$ in $\left.\mathrm{GPa}\right]$ & Carbonate rocks & Sachpazis (1990) \\
\hline (36) & & $2.28+4.1089 E_{\mathrm{S}}\left[E_{\mathrm{S}}\right.$ in $\left.\mathrm{GPa}\right]$ & Sandstones & Bradford et al. (1998) \\
\hline (37) & & $46.2 \mathrm{e}^{0.000027 E}[\mathrm{E}$ in $\mathrm{MPa}]$ & Sandstones & Chang et al. (2006) \\
\hline (38) & & $0.4067 \mathrm{E}^{0.51}[\mathrm{E}$ in $\mathrm{MPa}]$ & Limestones $(10<\mathrm{UCS}<300 \mathrm{MPa})$ & Chang et al. (2006) \\
\hline
\end{tabular}

UCS, uniaxial compressive strength; $\Phi$, porosity; $E_{\mathrm{S}}$, static Young's modulus; $\Delta t$, travel time; $v_{\mathrm{p}}, P$ wave velocity.

from the Middle Bunter and Lower Bunter (Thuringia, Germany) as well. The comparability of the equations is therefore also based on similar sedimentary conditions of the analysed rocks.

Equations (15a) and (15b) lead to much higher UCS values for high $v_{\mathrm{p}}$ than the relationship published by Kahraman (2001; Eq. 35), who considered not only carbonate samples. There are also bigger differences between our results and other equations (Eqs. 31, 32) which both include different kinds of rock. The regression function obtained by Sharma and Singh (2008), for example, is based on only three sandstone samples together with many other samples of different rock types (volcanic, sedimentary, and metamorphic) and therefore differs too much from the samples analysed in this study so that they cannot be compared. McNally (1987) published empirical relations of UCS- $\Delta t$ for different stratigraphic units in Australia. The functions relating to clastic units (Eqs. 29, 30) are comparable with Eq. (11b), but only for low $\Delta t$ values $\left(\Delta t<75 \mu \mathrm{ft}^{-1}\right.$; Fig. 8b).

In comparison with the two relationships presented above, UCS $-\Phi$ and UCS $-v_{\mathrm{p}}$, it is noteworthy that calculated regression functions for UCS $-E_{\mathrm{S}}$ of both carbonate rock samples and sandstones are in good accordance with previous studies (Table 6; Fig. 8c). Only the limestone function by Chang et al. (2006; Eq. 38) predicts higher UCS for small $E_{\mathrm{s}}$ values and lower UCS for high $E_{\mathrm{s}}$ values than Eq. (8c). The 
study of Chang et al. (2006), however, is not based on measurements of the static Young's modulus but of the dynamic Young's modulus. As discussed above, the comparability of dynamic and static Young's moduli is complicated because discontinuities have different effects on the measurements of the static Young modulus and acoustic wave propagation.

Overall, the obtained empirical relations are similar to equations developed in previous studies but, in some cases, show considerable differences. These variations mostly relate either to differences in lithologies the study is based on (Eqs. 31, 32), or to different ways of parameter determination (Eqs. 25, 38). The presented data set and empirical relations, however, give new and comprehensive information about mechanical and physical properties of sedimentary and volcanic rocks valid for the NWGB. Nevertheless, they are not only interesting for regional drilling projects or geomechanical modelling. They also supplement and enlarge the existing published results on rock properties, and the new relations may be applied to other sedimentary basins similar to the NWGB.

\section{Conclusions}

Geomechanical and physical parameters with importance in different stages of geothermal exploitation are measured for 35 outcrop samples from quarries and 14 core samples of the Northwest German Basin. Rock properties of these core samples are compared with results of outcrop samples by using regression analyses. The following conclusions can be made:

1. Simple regression analyses for UCS with the parameters porosity, bulk density, and $P$ wave velocity indicate that the statistical significance for these parameters is low. The developed equations yield distinct under- and over-predictions of UCS values. Data show, however, that properties of core samples fit perfectly well within the scatter of outcrop samples. That is, the developed regression functions work well for at least estimating core sample properties with comparatively small deviation. For drilling applications these equations are highly substantial because they allow a continuous update of the original geomechanical model with logging-whiledrilling methods for the calculation of optimum mud weights to avoid wellbore instabilities.

2. The developed empirical relations for Young's modulus, destruction work and indirect tensile strength with UCS show high statistical significance. Core samples plot within the $90 \%$ prediction bands. Regression analyses indicate that prediction of destruction work and tensile strength from UCS by outcrop data is possible. The applicability of these equations to rocks from greater depths is therefore assumed. The ratio between UCS and parameter values is the same for both outcrop and core samples. That is, data indicate that parameters of core sample are predictable from equations developed from an outcrop sample data set.

3. The presented data and regression equations may help to predict UCS values for sedimentary rocks at depth, and thus develop suitable geomechanical models for the adaptation of the drilling strategy on rock mechanical conditions in the Northwest German Basin and similar sedimentary basins.

Acknowledgements. The authors appreciate the support of the Niedersächsisches Ministerium für Wissenschaft und Kultur and "Baker Hughes" within the gebo research project (http://www. gebo-nds.de).

We thank the numerous owners for the permission to enter their quarries and to take samples. Special thanks to the LIAG (Leibniz Institute for Applied Geophysics) and BGR (Bundesamt für Geowissenschaften und Rohstoffe) in Hanover, Germany, for permission to sample the drill cores. We also thank the LIAG for the opportunity to perform density and porosity measurements. Review comments by I. Moeck and M. Heap helped in improving the manuscript.

This Open Access Publication is funded by the University of Göttingen.

Edited by: H. Rüter

Reviewed by: M. J. Heap and I. S. Moeck

\section{References}

Aggistalis, G., Alivizatos, A., Stamoulis, D., and Stournaras, G.: Correlating uniaxial compressive strength with Schmidt hardness, point load index, Young's modulus, and mineralogy of gabbros and basalts (Northern Greece), Bull. Int. Assoc. Eng. Geol., 54, 3-11, 1996.

Baud, P., Zhu, W., and Wong, T.-f.: Failure mode and weakening effect of water on sandstone, J. Geophys. Res.-Sol. Ea., 105, 16371-16389, 2000.

Betz, D., Führer, F., Greiner, G., and Plein, E.: Evolution of the Lower Saxony Basin, Tectonophysics, 137, 127-170, 1987.

Bradford, I. D. R., Fuller, J., Thompson, J., and Walsgrove, T. R.: Benefits of assessing the solids production risk in a North Sea reservoir using elastoplastic modelling, SPE/ISRM Eurock '98, Trondheim, 261-269, 1998.

Brink, D.: Essentials of Statistics, 2nd Edn., David Brink \& Ventus Publishing, available at: http://www.bookboon.com (last access: January 2014), ISBN:978-87-7681-408-3, 2010.

Chang, C., Zoback, M. D., and Khaksar, A.: Empirical relations between rock strength and physical properties in sedimentary rocks, J. Petrol. Sci. Eng., 51, 223-237, 2006.

Çobanoğlu, I. and Çelik, S. B.: Estimation of uniaxial compressive strength from point load strength, Schmidt hardness and $P$ wave velocity, B. Eng. Geol. Environ., 67, 491-498, 2008.

Dinçer, I., Acar, A., Çobanoğlu, I., and Uras, Y.: Correlation between Schmidt hardness, uniaxial compressive strength and Young's modulus for andesites, basalts and tuffs, B. Eng. Geol. Environ., 63, 141-148, 2004. 
Dusseault, M. B.: Geomechanical challenges in petroleum reservoir exploitation, KSCE J. Civ. Eng., 15, 669-678, 2011.

Edlmann, K., Somerville, J. M., Smart, B. G. D., Hamilton, S. A., and Crawford, B. R.: Predicting rock mechanical properties from wireline porosities, SPE/ISRM Eurock 47344, 1998.

Fossen, H.: Structural Geology, Cambridge University Press, New York, 2010.

Freyburg, E.: Der Untere und Mittlere Buntsandstein SWThüringen in seinen gesteinstechnischen Eigenschaften, Ber. Dtsch. Ges. Geol. Wiss. A Berlin, 17, 911-919, 1972.

Fricke, S. and Schön, J.: Praktische Bohrlochgeophysik, Enke, Stuttgart, 1999.

Gebrande, H., Kern, H., and Rummel, F.: Elasticity and inelasticity, in: Landolt-Bornstein Numerical Data and Functional Relationship in Science and Technology, New Series, edited by: Hellwege, K.-H., GroupV. Geophys. Space Res., 1, Physical Properties of Rocks, Subvolume b. Springer, Berlin, 233 pp., 1982.

Gudmundsson, A.: Rock Fractures in Geological Processes, Cambridge University Press, New York, 2011.

Heap, M. J., Faulkner, D. R., Meredith, P. G., and Vinciguerra, S.: Elastic moduli evolution and accompanying stress changes with increasing crack damage: implications for stress changes around fault zones and volcanoes during deformation, Geophys. J. Int., 183, 225-236, 2010

Hobbs, D. W.: The tensile strength of rocks, Int. J. Rock Mech. Min., 1/3, 385-396, 1964.

Huang, T. H., Chang, C. S., and Yang, Z. Y.: Elastic moduli for fractured rock mass, Rock Mech. Rock Eng., 28, 135-144, 1995.

ISRM: The Complete ISRM Suggested Methods for Rock Characterization, Testing and Monitoring: 1974-2006. Suggested Methods Prepared by the Commission on Testing Methods, International Society for Rock Mechanics, Ulusay, R. and Hudson, J. A., Compilation Arranged by the ISRM Turkish National Group, Ankara, Turkey, 2007.

Jaeger, J. C., Cook, N. G. W., and Zimmerman, R. W.: Fundamentals of Rock Mechanics, Blackwell, Malden USA, 2007.

Jizba, D. L.: Mechanical and Acoustical Properties of Sandstones, Dissertation, Stanford University, 1991.

Kahraman, S.: Evaluation of simple methods for assessing the uniaxial compressive strength of rock, Int. J. Rock Mech. Min., 38, 981-994, 2001.

Kahraman, S.: The correlations between the saturated and dry $P$ wave velocity of rocks, Ultrason, 46, 341-348, 2007.

Karakul, H. and Ulusay, R.: Empirical correlations for predicting strength properties of rocks from $P$ wave velocity under different degrees of saturation, Rock Mech. Rock Eng., 46, 981-999, 2013.

Khaksar, A., Taylor, P. G., Kayes, T., Salazar, A., and Rahman, K.: Rock strength frlom Core and logs: Where we stand and ways to go, SPE EUROPEC/EAGE, 121972, 2009.

Lama, R. D. and Vutukuri, V. S.: Handbook on Mechanical Properties of Rocks - Testing Techniques and Results, Vol. II. Trans Tech Publications, Clausthal, 1978.

Li, S., George, J., and Purdy, C.: Pore-pressure and wellborestability prediction to increase drilling efficiency, J. Petrol. Technol., 64, 99-101, 2012.

Lockner, D. A.: Rock Failure, Rock physics and phase relations, American Geophysical Union, Washington D.C., 127-147, 1995.
Martínez-Martínez, J., Benavente, D., and García-del-Cura, M. A.: Comparison of the static and dynamic elastic modulus in carbonate rocks, B. Eng. Geol. Environ., 71, 263-268, 2012.

McNally, G. H.: Estimation of coal measures rock strength using sonic and neutron logs, Geoexploration, 24, 381-395, 1987.

Nabaei, M. and Shahbazi, K.: A new approach for predrilling the unconfined rock compressive strength prediction, Pet. Sci. Technol., 30/4, 350-359, 2012.

Nur, A. and Simmons, G.: The effect of saturation on velocity in low porosity rocks, Earth Planet. Sc. Lett., 7, 183-193, 1969.

Palchik, V.: Influence of porosity and elastic modulus on uniaxial compressive strength in soft brittle porous sandstones, Rock Mech. Rock Eng., 32, 303-309, 1999.

Paschen, H., Oertel, D., and Grünwald, R.: Möglichkeiten geothermischer Stromerzeugung in Deutschland, TAB Arbeitsbericht 84, 2003.

Popp, T. and Kern, H.: The influence of dry and water saturated cracks on seismic velocities of crustal rocks - A comparison of experimental data with theoretical model, Surv. Geophys., 15, 443-465, 1994.

Priest, S. D.: Discontinuity Analysis for Rock Engineering, Chapman and Hall, London, 1993.

Proehl, T. S.: Geomechanical uncertainties and exploratory drilling costs, SPE/ISRM Rock Mechanics Conference, Irving, USA, 2002.

Rajabzadeh, M. A., Moosavinasab, Z., and Rakhshandehroo, G.: Effects of rock classes and porosity on the relation between uniaxial compressive strength and some rock properties for carbonate rocks, Rock Mech. Rock Eng., 45, 113-122, 2012.

Reyer, D., Bauer, J. F., and Philipp, S. L.: Fracture systems in normal fault zones crosscutting sedimentary rocks, Northwest German Basin, J. Struct. Geol., 45, 38-51, 2012.

Rider, M. and Kennedy, M.: The Geological Interpretation of Well Logs, Rider-French Consulting Ltd., 2011.

Sachpazis, C. I.: Correlating Schmidt hammer rebound number with compressive strength and Young's modulus of carbonate rocks, Bull. Int. Assoc. Eng. Geol., 42, 75-83, 1990.

Sammis, C. G. and Ashby, M. F.: The failure of brittle porous solids under compressive stress states, Acta. Metall. Mater., 34, 511526, doi:10.1016/0001-20656160(86)90087-8, 1986.

Settari, A. and Walters, D. A.: Advances in coupled geomechanical and reservoir modeling with applications to reservoir compaction, SPE 74142, SPEJ (September 2001), 335-342, 2001.

Shakoor, A. and Barefield, E. H.: Relationship between unconfined compressive strength and degree of saturation for selected sandstones, Environ. Eng. Geosci., 15, 29-40, 2009.

Sharma, P. K. and Singh, T. N.: A correlation between $P$ wave velocity, impact strength index, slake durability index and uniaxial compressive strength, B. Eng. Geol. Environ., 67, 17-22, 2008.

Thuro, K.: Drillability prediction: geological influences in hard rock drill and blast tunnelling, Geol. Rundsch., 86, 426-438, 1997.

Vásárhelyi, B.: Statistical analysis of the influence of water content on the strength of the miocene limestone, Rock Mech. Rock Eng., 38, 69-76, 2005.

Vernik, L., Bruno, M., and Bovberg, C.: Empirical relations between compressive strength and porosity of siliciclastic rocks, Int. J. Rock Mech. Min., 30, 677-680, 1993.

Vogt, E., Reyer, D., Schulze, K. C., Bartetzko, A., and Wonik, T.: Modeling of geomechanical parameters required for safe drilling 
of geothermal wells in the North German Basin, Celle Drilling, Celle, Germany, 2012.

Walter, R.: Geologie von Mitteleuropa. Schweizerbarth, Stuttgart, 2007.

Wong, T.-F., David, C., and Zhu, W.: The transition from brittle faulting to cataclastic flow in porous sandstones: mechanical deformation, J. Geophys. Res., 102, 3009-3025, 1997.

Wooldridge, J. M.: Introductory Econometrics: A Modern Approach, 4th Edn. Mason: South-Western, Cengage Learning, 2009.

York, P., Pritchard, D., Dodson, J. K., Rosenberg, S., Gala, S., and Utama, B.: Eliminating non-productive time associated with drilling trouble zones, Offshore Technology Conference 2009, Houston, USA, 2009.

You, M.: Effect of confining pressure on the Young's modulus of rock specimen, Chin. J. Rock Mech. Eng., 22, 53-60, 2003.
Zamora, M., Sartoris, G., and Chelini, W.: Laboratory measurements of ultrasonic wave velocities in rocks from the Campi Flegrei volcanic system and their relation to other field data, J. Geophys. Res., 99, 13553-13561, 1994.

Zeynali, M. E.: Mechanical and physico-chemical aspects of wellbore stability during drilling operations, J. Petrol. Sci. Eng., 8283, 120-124, 2012.

Zhu, W., Baud, P., Vinciguerra, S., and Wong, T.-F.: Micromechanics of brittle faulting and cataclastic flow in Alban Hills tuff, J Geophys. Res.-Sol. Ea., 116, B06209, doi:10.1029/2010JB008046, 2011.

Ziegler, P.: Geological Atlas of Western and Central Europe, Geological Society Publishing House/Shell International Petroleum Maatschappij B.V., 1990.

Zoback, M. D.: Reservoir Geomechanics, Cambridge University Press, New York, 2007. 